www.refaad.com
المجلة الدولية للدراسات القانونية والفقهية المقارنة

International Journal of Legal and Comparative Jurisprudence Studies (LCJS)

Journal Homepage: https://www.refaad.com/views/LCJS/Home.aspx

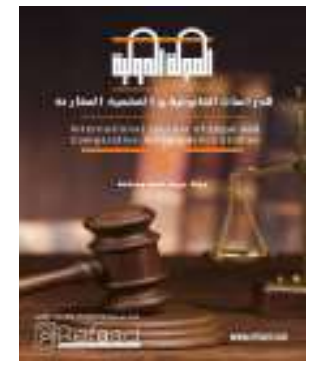

\title{
جريمة الإبادة الجماعية في ظل المحاكم الجنائية الخاصة والمحكمة الجنائية الدولية
}

\section{(دراسة تحليلية)}

\author{
عمر محممد موسى اسماعيل \\ أستاذ مساعد- قسم القانون - جامعة شقراء- المملكة العربية السعودية
}

omar.mi@su.edu.sa

DOI: https://doi.org/DOI:10.31559/LCJS2020.1.1.1

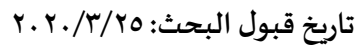

r.r.r/T/ Tاريخ استلام البحث

يركز موضوع هذا البحث على جريمة الإبادة الجماعية من حيث أساس الظهور لهذه الجريمة والتعريفات التي تناولتها الاتفاقيات الدولية

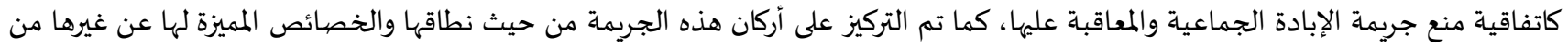

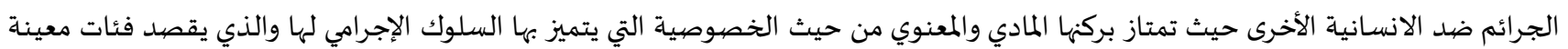

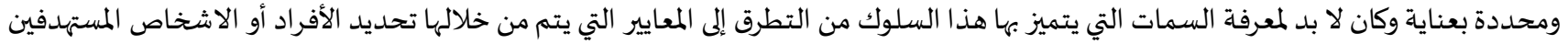

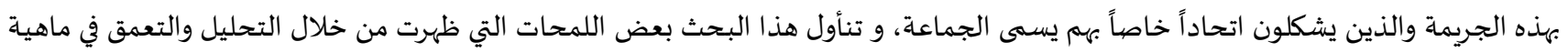

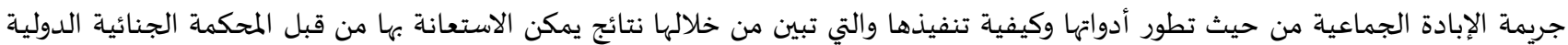
الدائمة والمشرع الدولي.

الكلمات المفتاحية: الإبادة الجماعية؛حقوق الانسان؛ محاكم جنائية؛ الاتفاقيات الدولية؛جريمة؛ قانون.

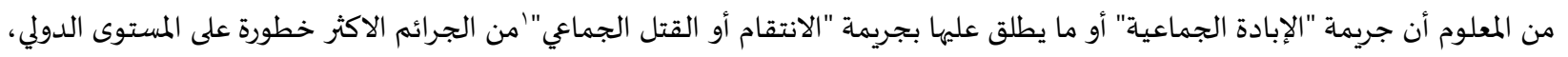

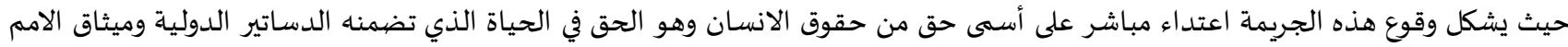

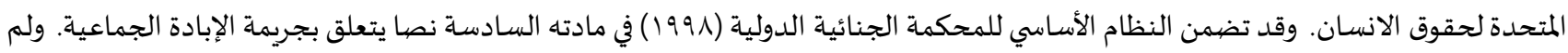

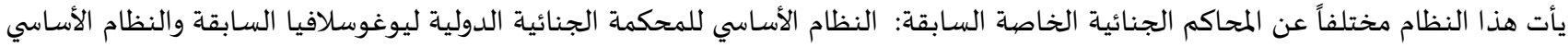

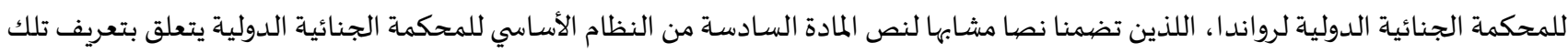

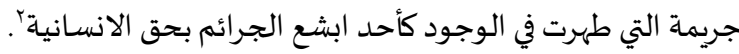

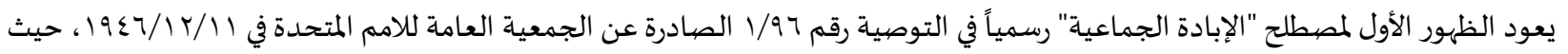

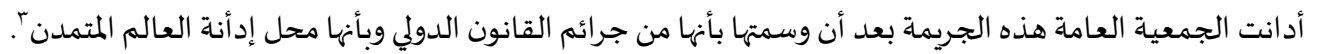

'زياد احمد محمد العبادي- دور المحاكم الجنائية الدولية الخاصة في تحديد جريمة الإبادة الجماعية - رسالة استكمالا للحصول على درجة الماجستير في القانون العام - جامعة

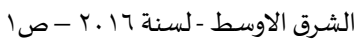

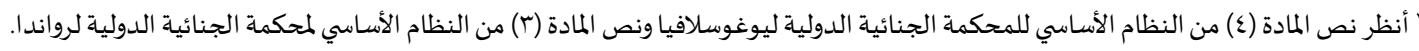

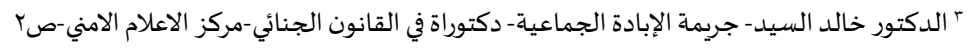


إلا أن هذا الظهور يعود في حقيقته إلى عام ع£ 19 من خلال ( Rephael Lemkin) الفقيه ليمكين الذي اطلقه في دراسة اجراها خلال ذلك العام

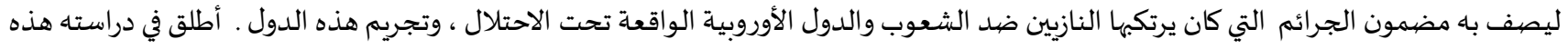

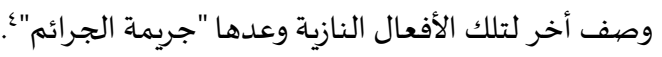
غير أن البعض يدلل بأن أولى هذه الاستخدامات رسمياً كانت تعود إلى معاهدة (سيفر سنة . . ب 19) ولكن ليس حرفياً وأنما أطلق عليها جريمة إبادة الجنس البشري وكان المقصود هو جريمة الإبادة الجماعية.

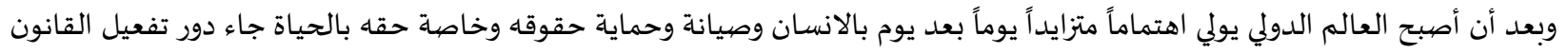

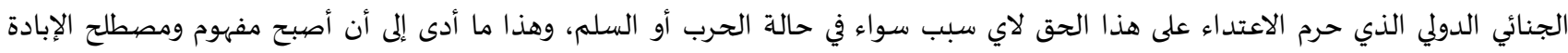

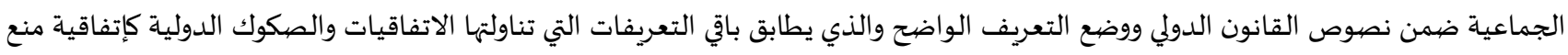

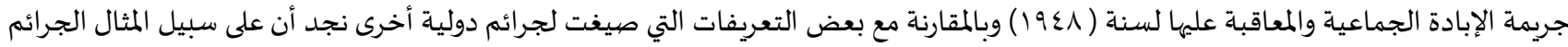

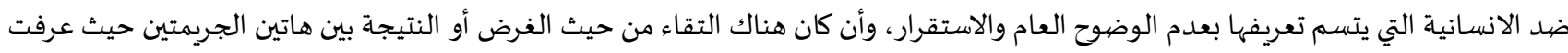

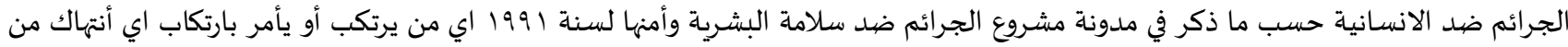

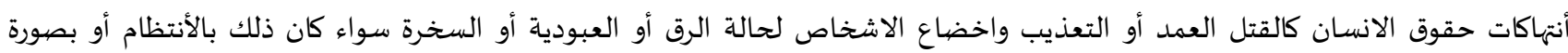
جماعية". أن ما يجمع بين هاتين الجريمتين واضح من المفهوم السابق ذلك أن كل منهما يؤدي إلى إنهاء حياة الانسان.

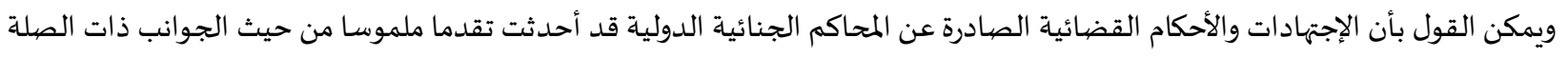

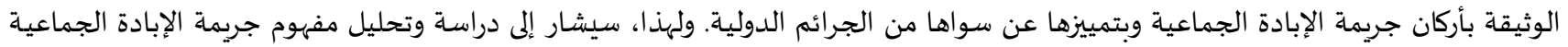

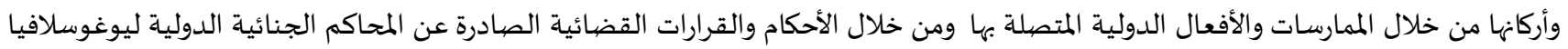

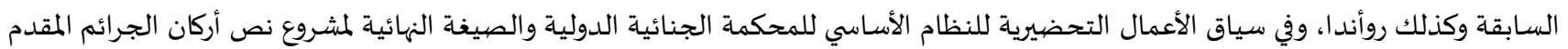

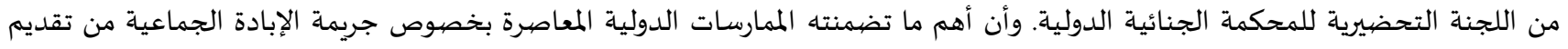

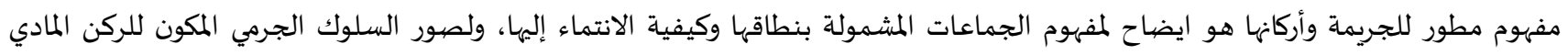

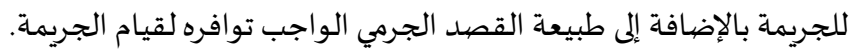

أهمية البحث:

تنبع أهمية هذا البحث من أهمية جريمة الإبادة الجماعية وخطورتها على المجتمع الدولي حيث أهها ترمي إلى إبادة الجنس البشري وهذا الهدف أو أو أنها

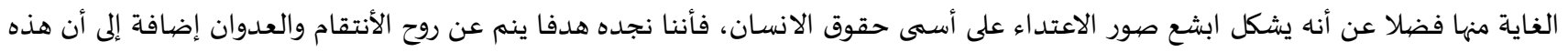

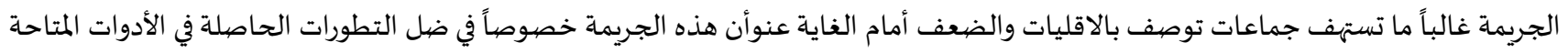

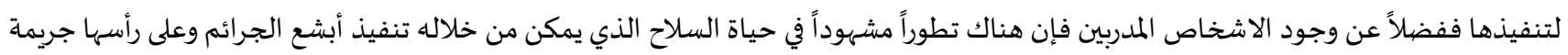
الإبادة الجماعياة وبالتالي لابد من التصدي لهذه الجريمة لما في ذلك من صيانة حق الحياة الذي يعد من أسمى حقوق الانسان المعتر ف به بموجب الاتفاقيات الدولية والشريعة البشرية.

إشكالية البحث: من خلال ما تقدم بأن جريمة الإبادة الجماعية من أخطر الجرائم الدولية والتي ترمي إلى الاعتداء على أسمى حقوق الانسان وبالتالي لا بد من بيان

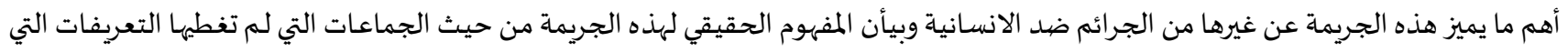

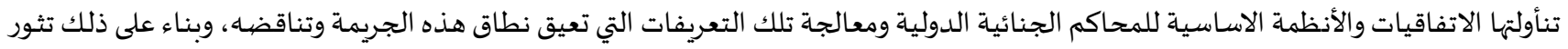
لدينا التساؤلات التالية:

$$
\text { هل قامت المحكمة الجنائية الدولية بالتغيير من هذا المفهوم؟ }
$$

وكيف تصدى المجتمع الدولي لهذه الجريمة منذ ظهورها حتى يومنا هذا؟ نهاميا

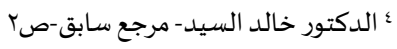

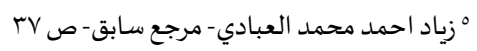

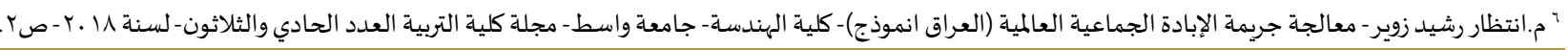


يهدف هذا البحث إلى معالجة الاشكاليات التي تتمثل بعدم ظبط جريمة الإبادة الجماعية والتي تقودنا إلى النتائج والتوصيات التي يمكن من

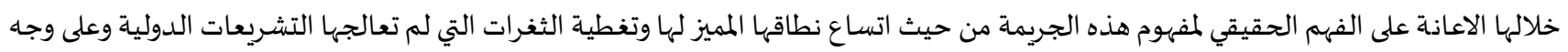
الخصوص النظام الاساسي للمحكمة الجنائية الدولية الدائمة.

منهجية البحث:

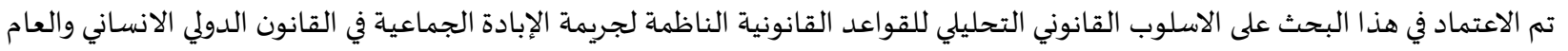

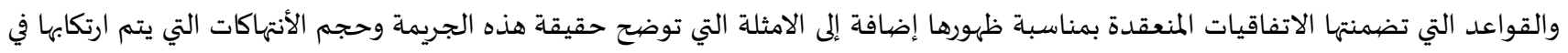

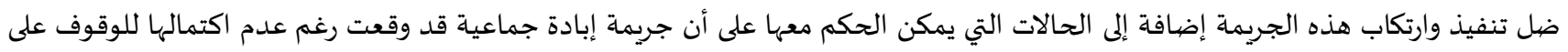

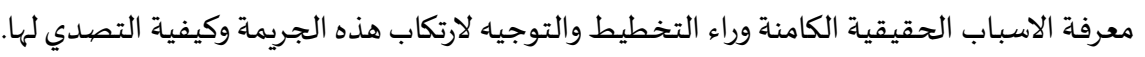

خطة البحث:

المبحث الأول : تعريف ونطاق جريمة الإبادة الجماعية

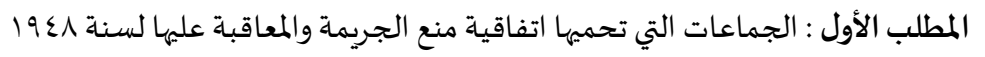

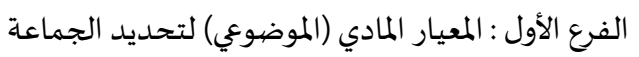

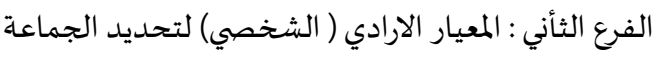

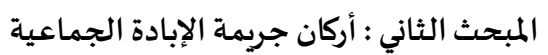

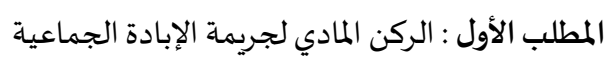

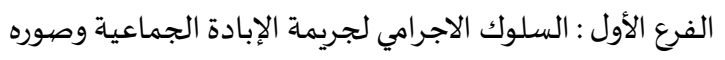

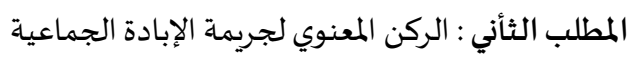

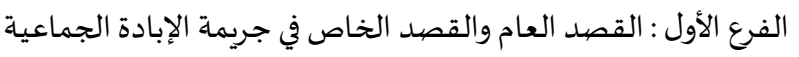

المبحث الأول : تعريف ونطاق جريمة الإبادة الجماعية

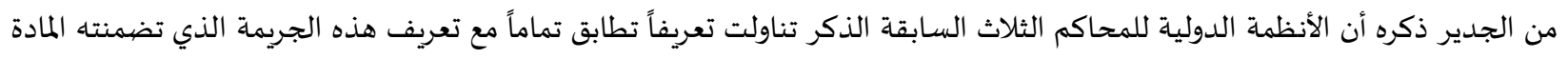

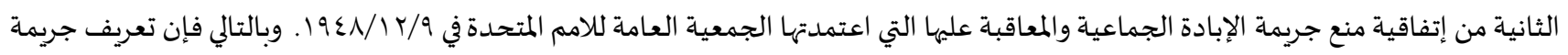

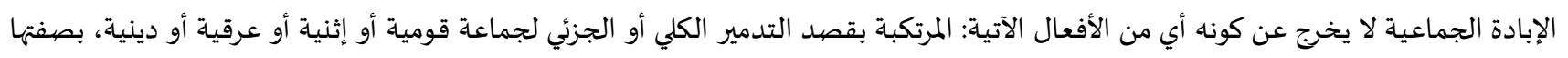

$$
\begin{aligned}
& \text { هذه: }
\end{aligned}
$$

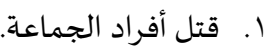

$$
\begin{aligned}
& \text { r. إلحاق ضرر جسدي أو عقلي جسيم بأفراد الجماعة. }
\end{aligned}
$$

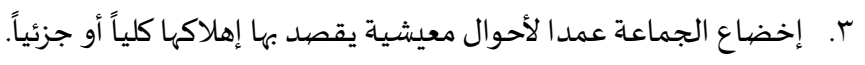

$$
\begin{aligned}
& \text { ع. فرض تدابير تستهدف منع الأنجاب داخل الجماعة. }
\end{aligned}
$$

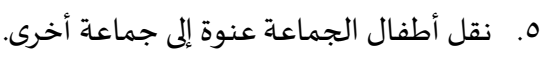

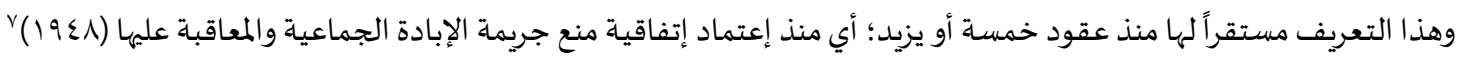

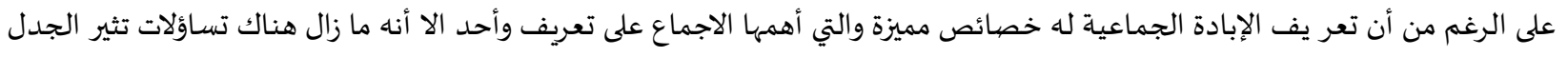

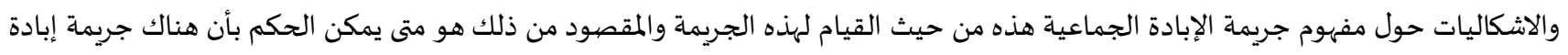

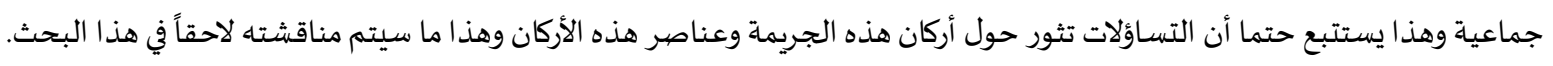

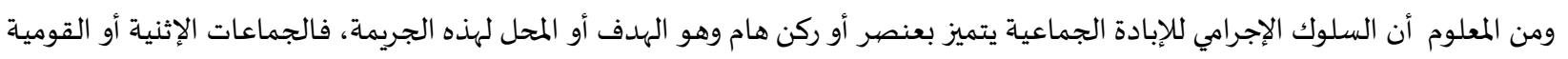

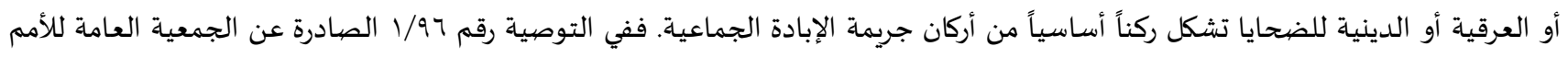

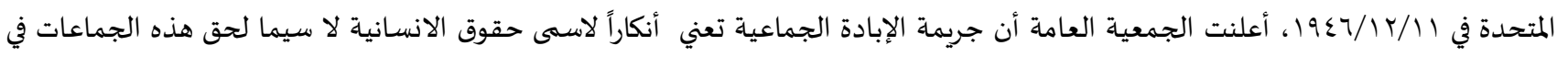

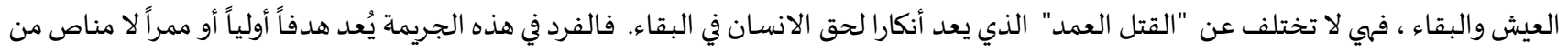

> اتفاقية منع جريمة الإبادة الجماعية والمعاقبة عليها لسنة 19 19 . 


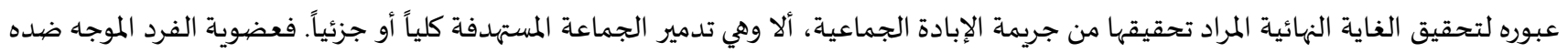

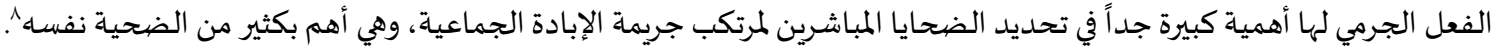

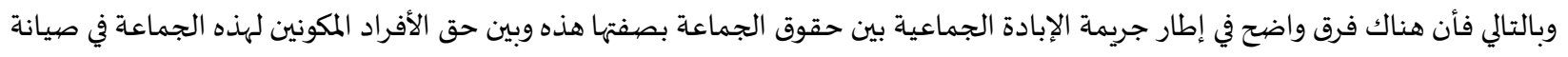

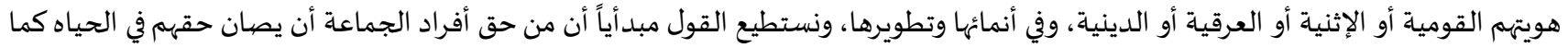

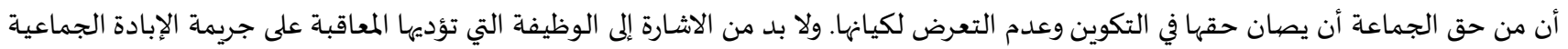

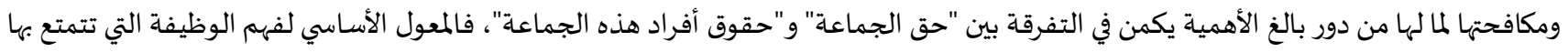

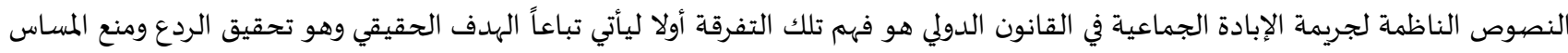

باسمى حق من حقوق الانسان.

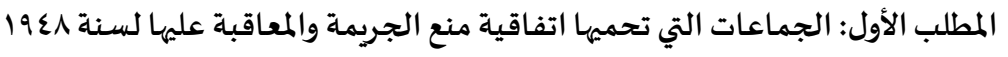

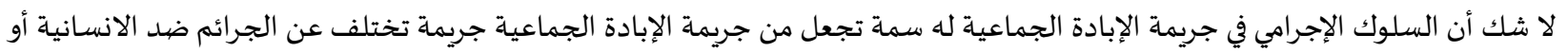

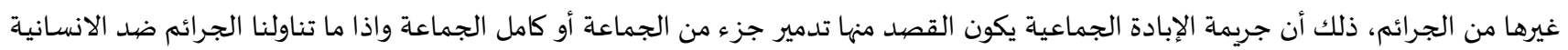

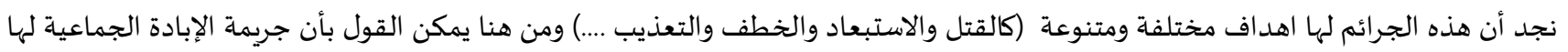

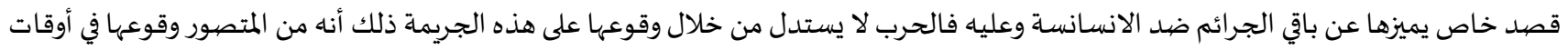

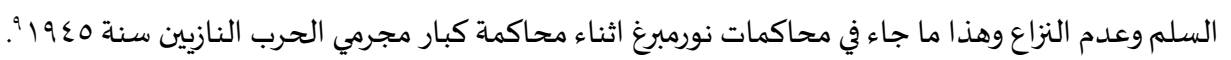

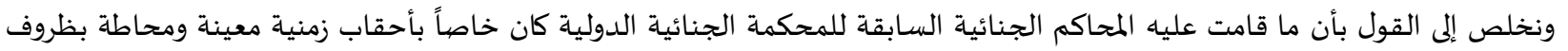

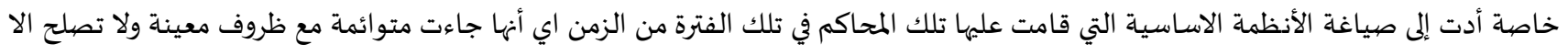

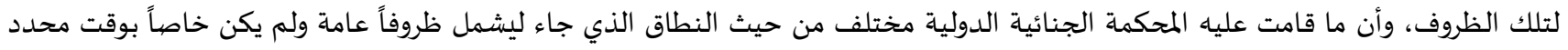

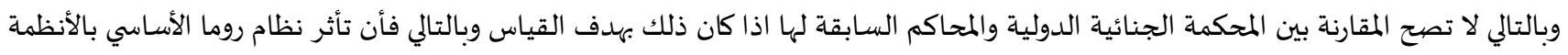

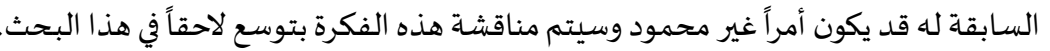

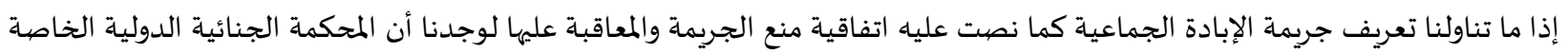

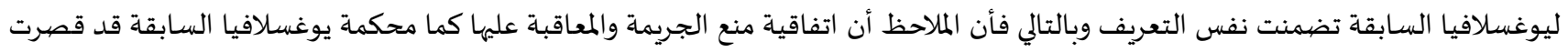

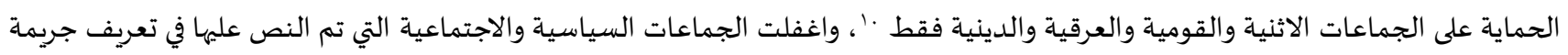

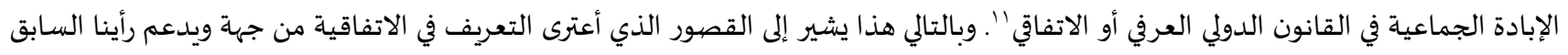

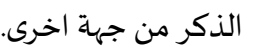

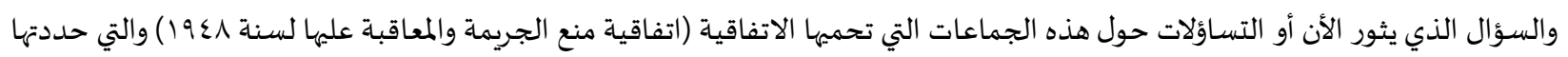

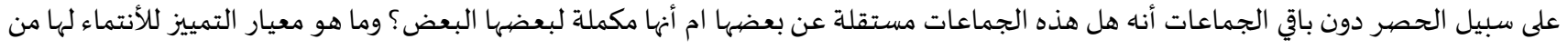

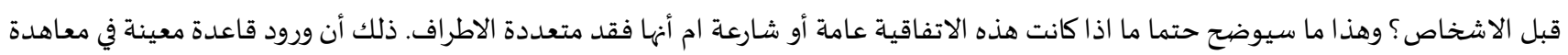

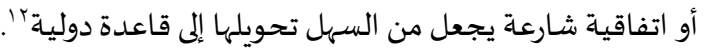

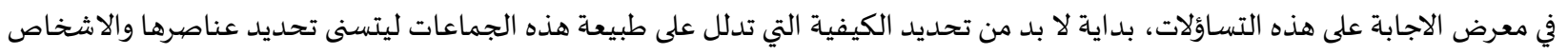

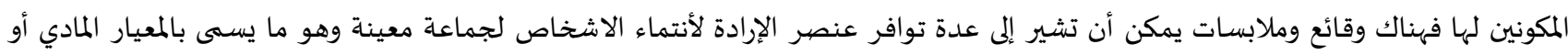

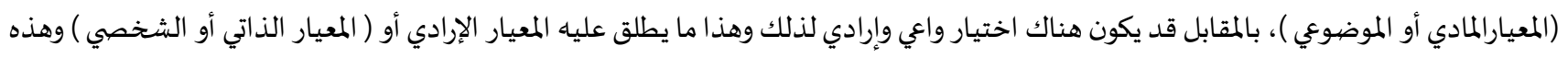

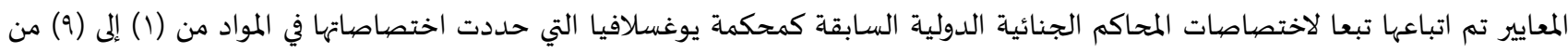

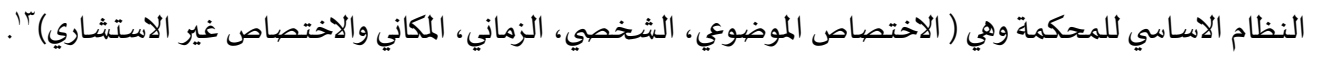

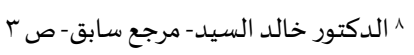

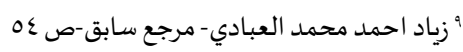

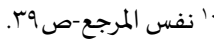

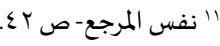

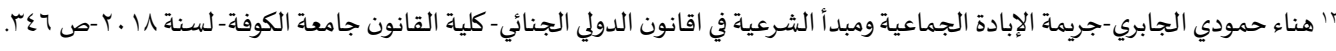

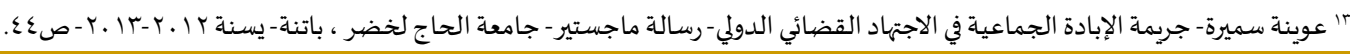




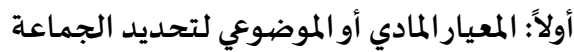

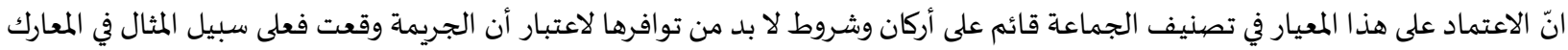

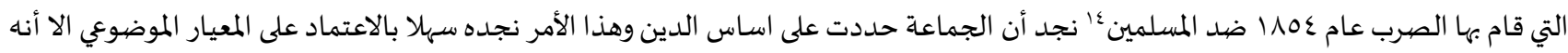

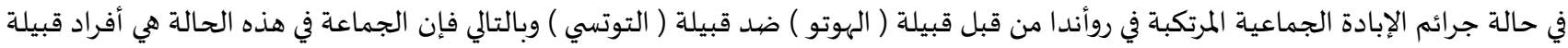

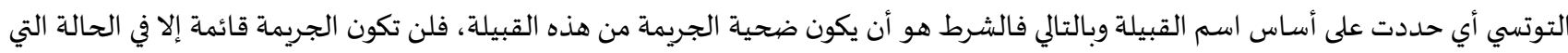

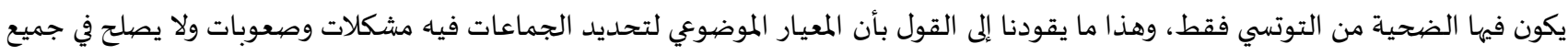

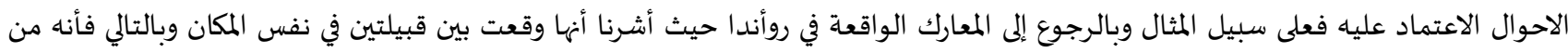

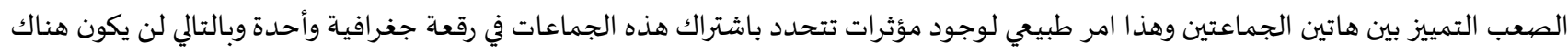

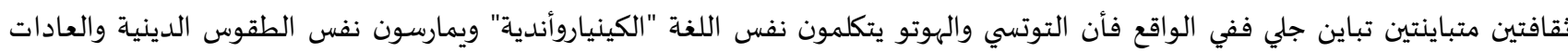

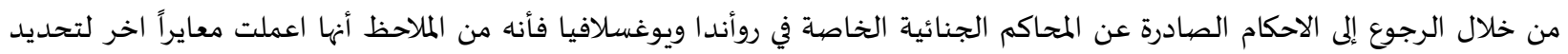

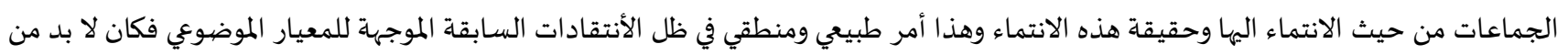

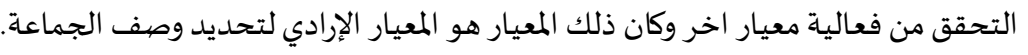

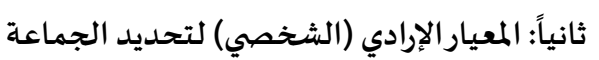

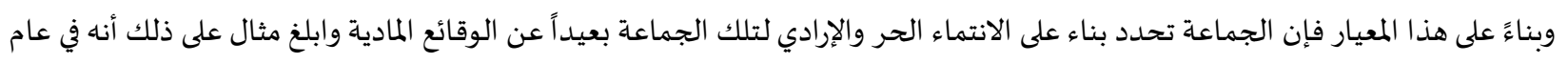

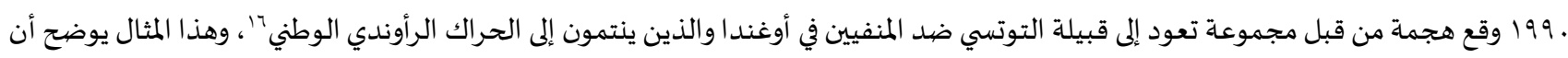
الانتماء أنما كان بإرادة الاشخاص الذين الذين اختاروا الجبهة الوطنية.

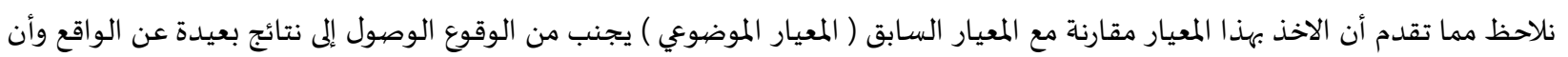

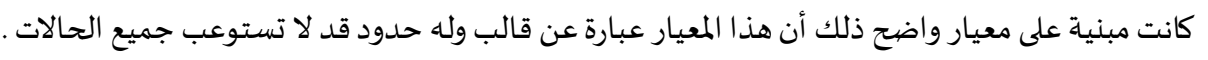

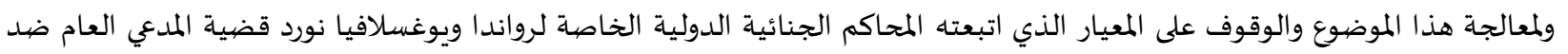

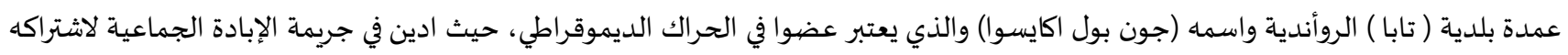

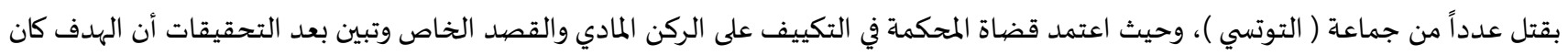

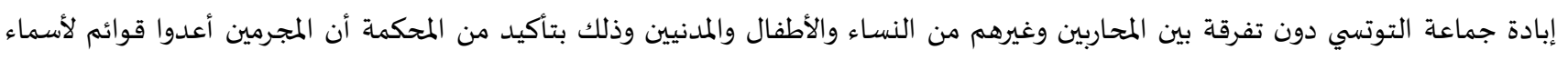

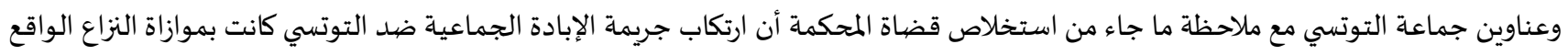

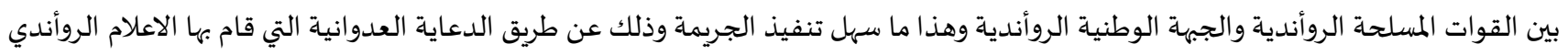

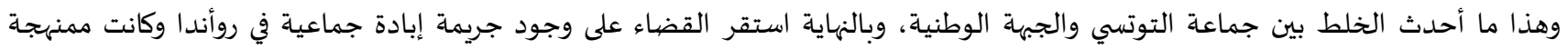

ومدروسة مسبقال.

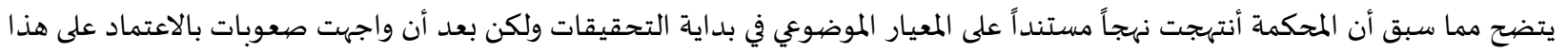

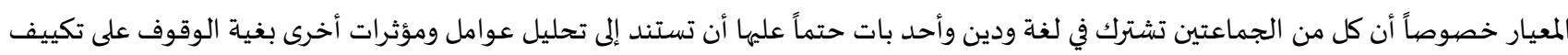

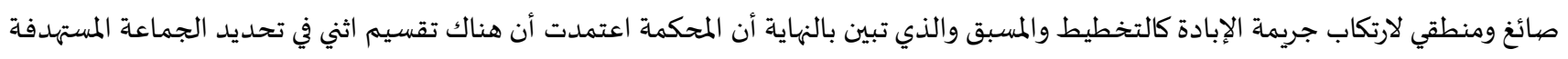

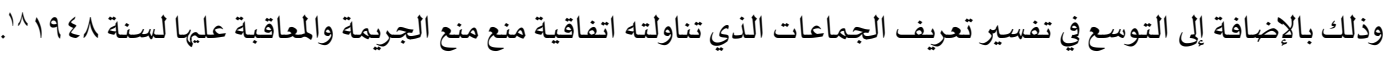

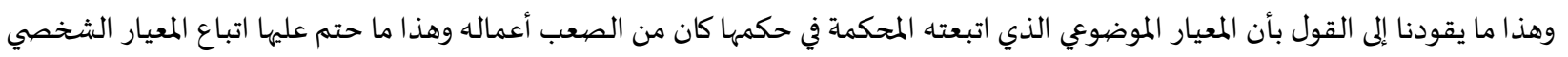

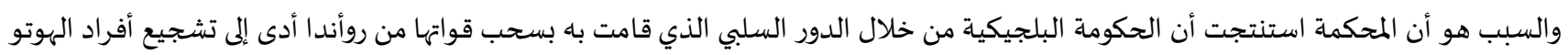

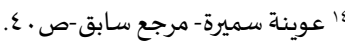

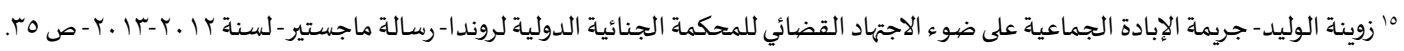

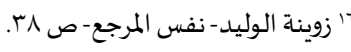

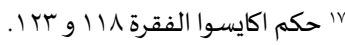

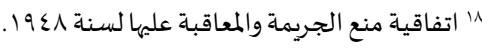


على استهداف كل فرد من التوتسي اي أنها خلفت باستعمارها تقسيمات اثنيةج"، ( الهوتو والتوتسي ) بشكل رئيسي إضافة إلى التأواسي وبالتالي أصبح

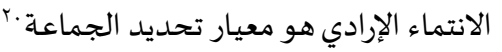

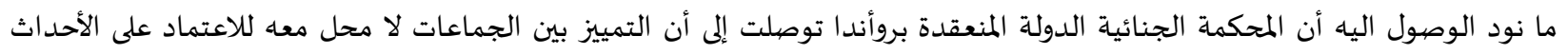

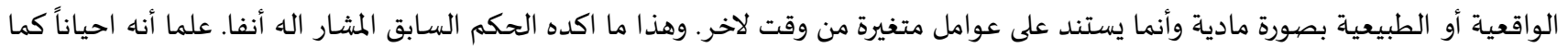

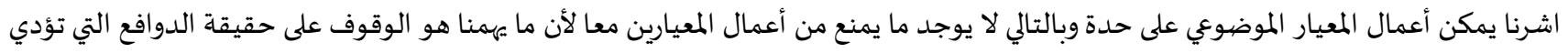

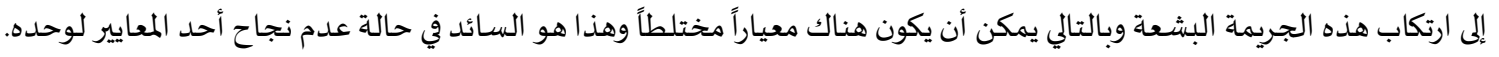

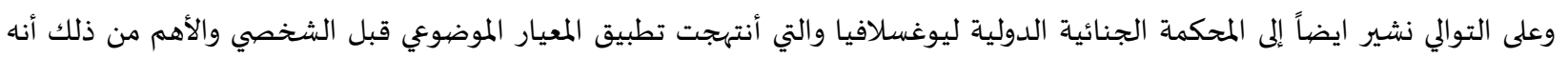

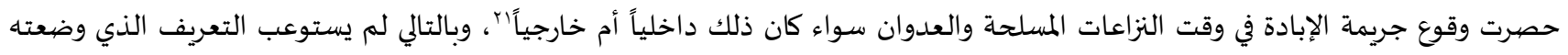

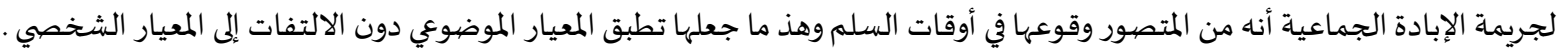

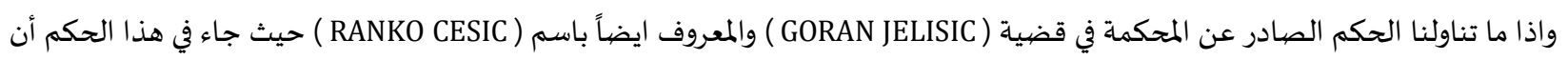

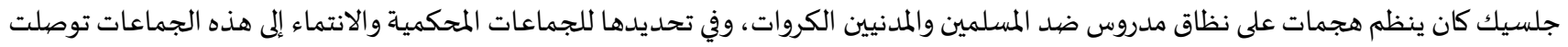

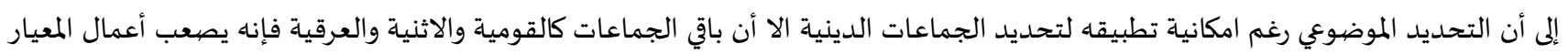

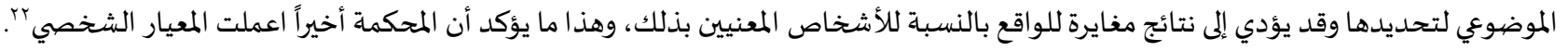

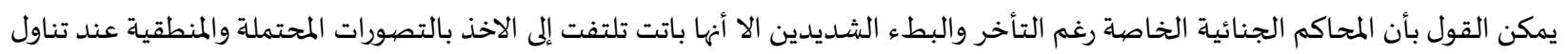

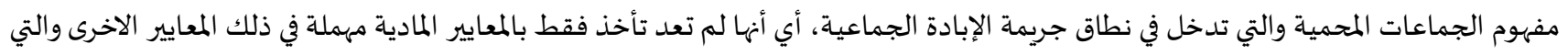

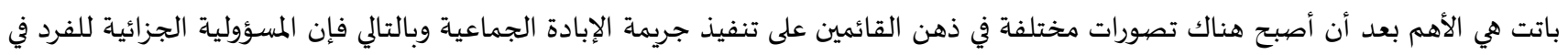

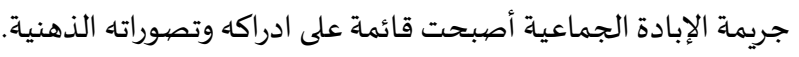

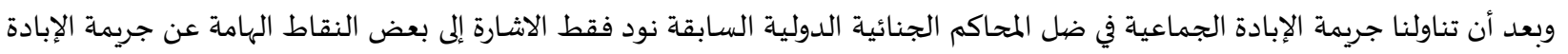

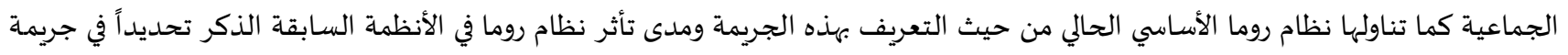

الإبادة الجماعية.

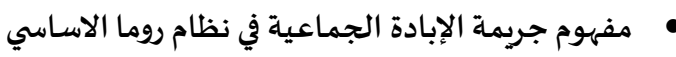

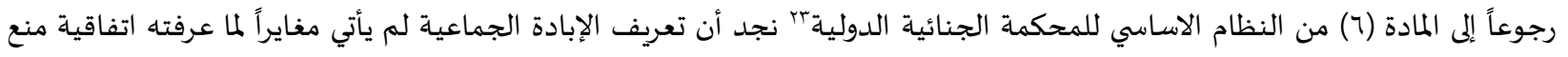

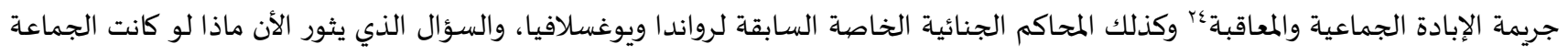

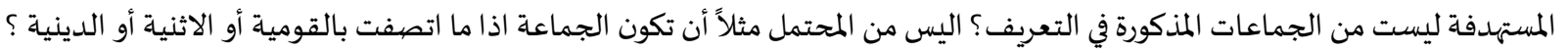

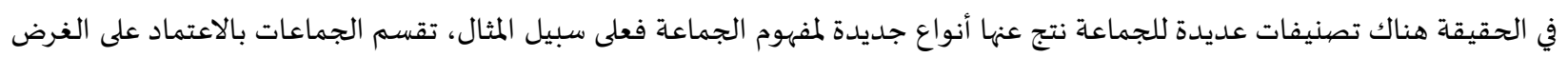

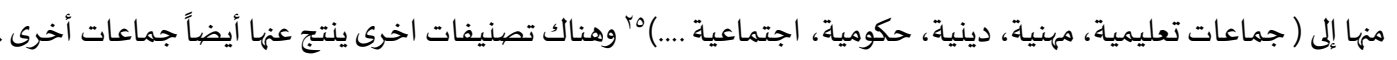

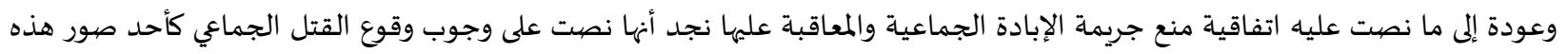

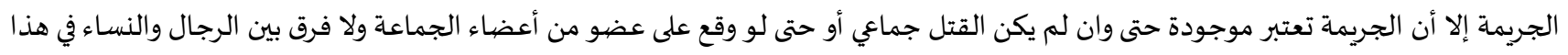

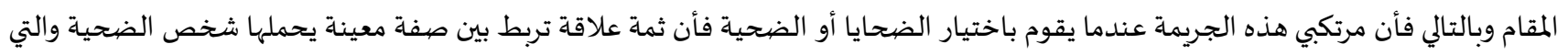

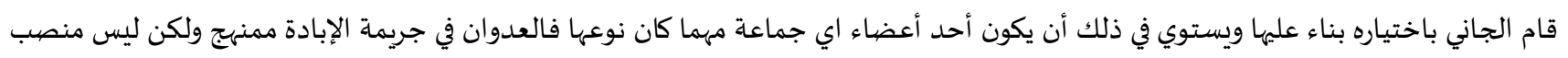

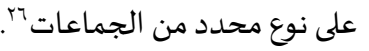

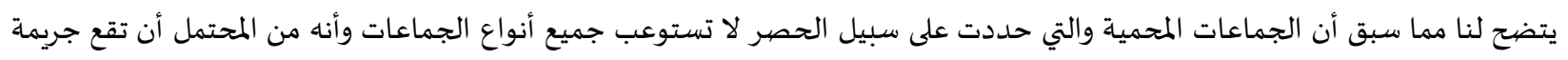

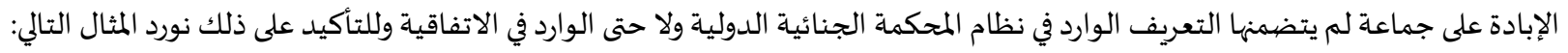

19 زوينة الوليد- مرجع سابق-ص 00.

${ }^{20}$ Senat de belqiqe, op cit.

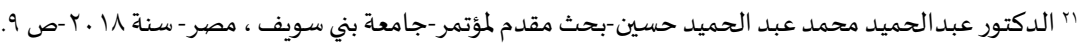
22 The international criminal tribunal for the former Yugoslavia-case no. ti,95,10, pt-1998.

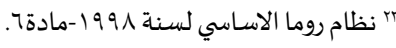

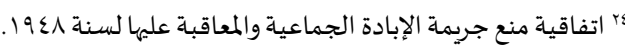

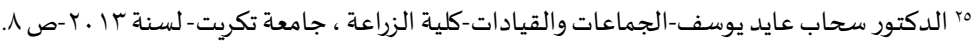

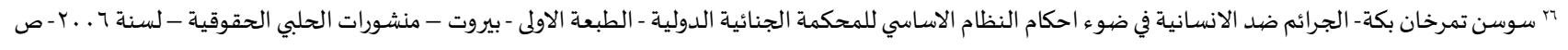

r.TO 
في الأحداث التي وقعت في اقليم دارفور تم تعيين لجنة للبحث والتدقيق في التقارير الخاصة بخرق وانتهاكات القانون الدولي الإنساني والقانون

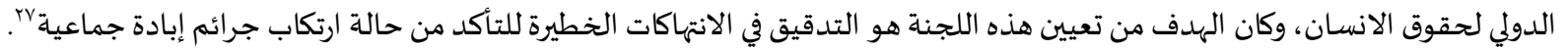

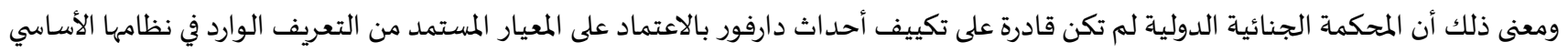

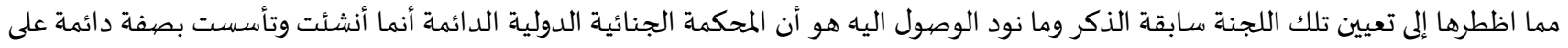

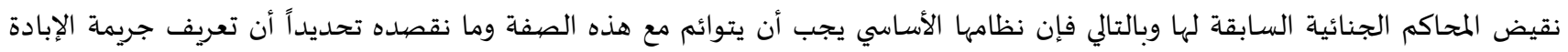

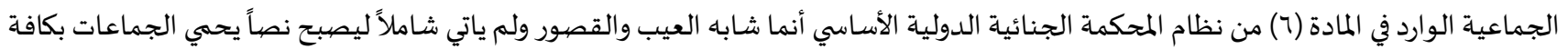

المفاهيم وخصوصاً المستحدثة منها.

\section{المبحث الثاني: أركان جريمة الإبادة الجماعية}

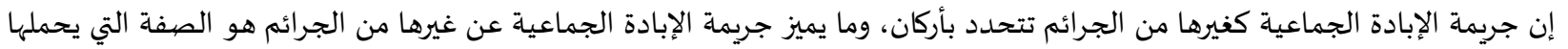

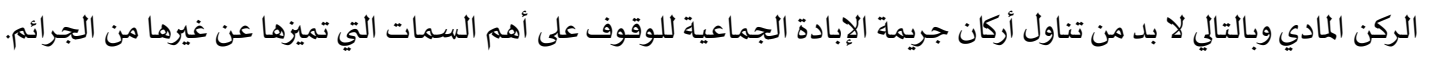

المطلب الأول: الركن المادي لجريمة الإبادة الجماعية

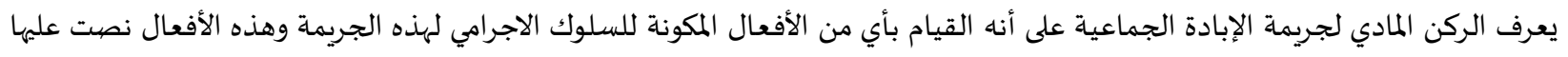

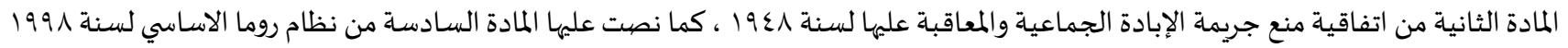

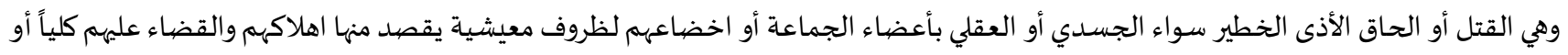

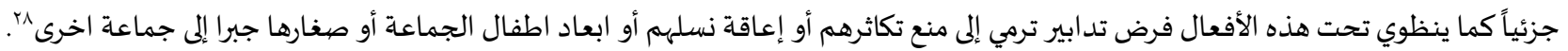

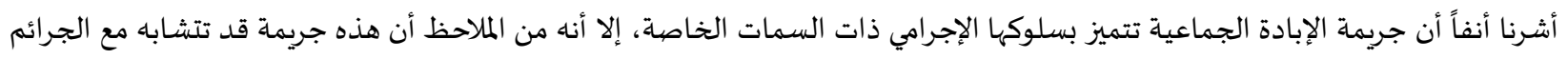

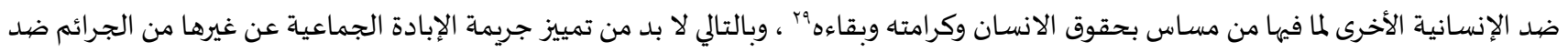
الانسانية وسيتم ذلك من خلال استكمال أركان جريمة الإبادة الجماعية.

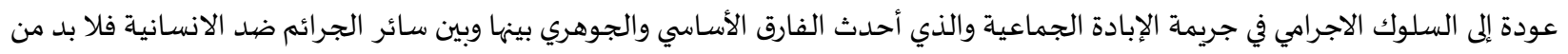

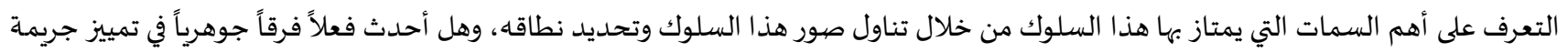
الإبادة الجماعية عن غيرها من الجرائم.

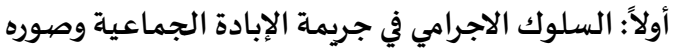

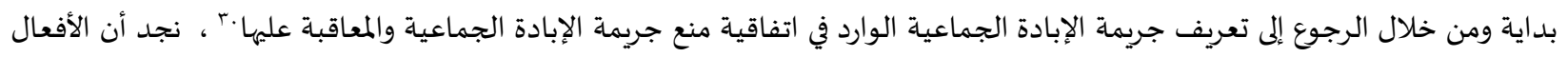

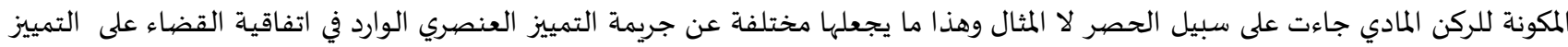

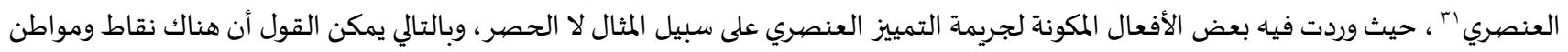

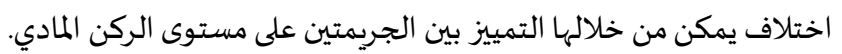

ثانياً: صور السلوك الإجرامي: وهذه الصور تتمثل باي من الأفعال المنصوص عليها في تعريف الإيفائ جريمة الإبادة الجماعية الوارد في اتفاقية منع جريمة الإبادة الجماعية والمعاقبة علهيها

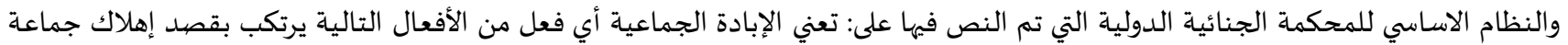
قومية أو اثنية أوعرقية أو دينية بصفتها هذه إهلاكاً كلياً أو جزئياً :

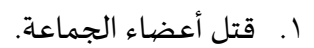

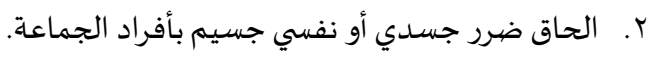

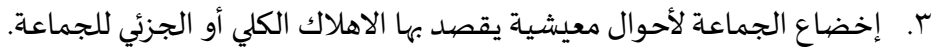
ع. فرض تدابير يستهدف منها منع الإنجاب داخل الجماعة.

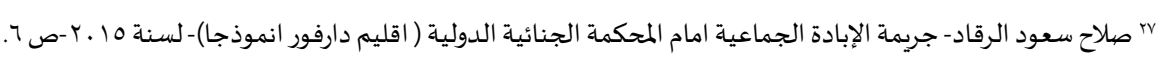

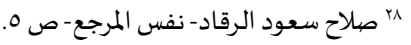

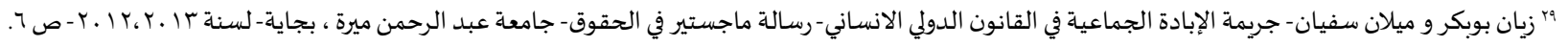

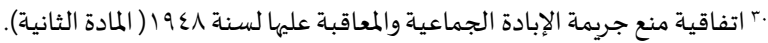

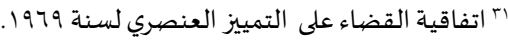


0. نقل أطفال الجماعة عنوة إلى جماعة أخرى بَّ.

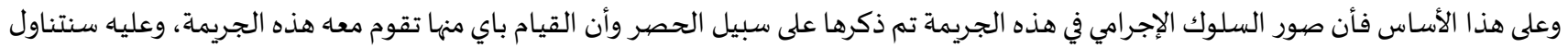

هذه الصور تفصيلا فيما يلي:

• قتل اعضاء الجماعة: والمقصود هنا هو تحقق واقعة القتل بصرف النظر عن الوسيلة أو الالية لتحقيق ذلك كما لا يشترط العدد اي أن واقعة

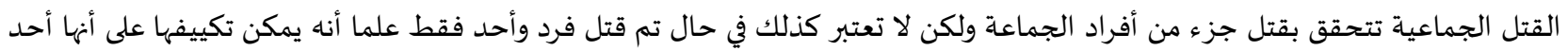

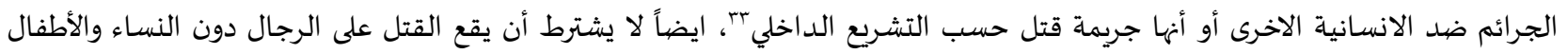

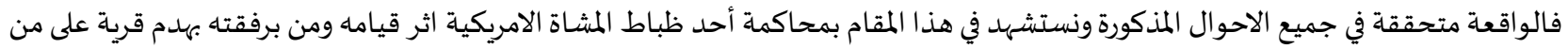

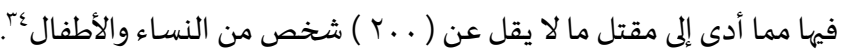

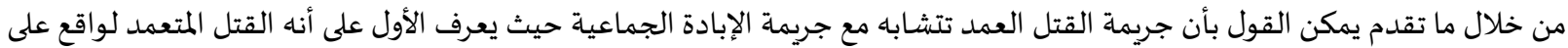

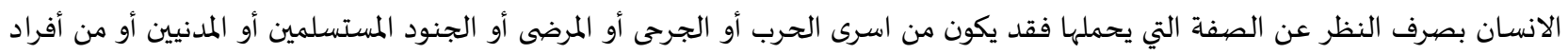

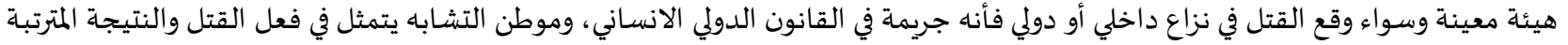

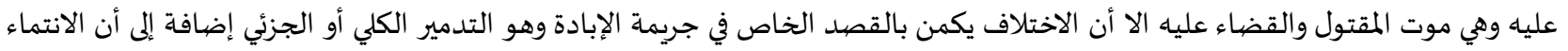

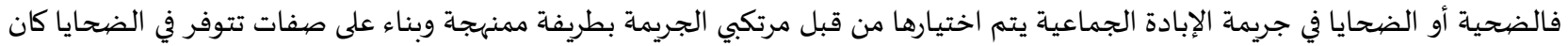

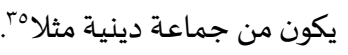
ويمكن القول بناء على ما تقدم أن القتل في كلتا الجريمتين يجب أن يكون عن قصد لأنه لا يتصور أن يشكل القتل غير المقصيود ركن جريمة الإبادة الجماعية المادي.

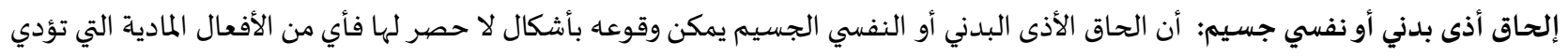

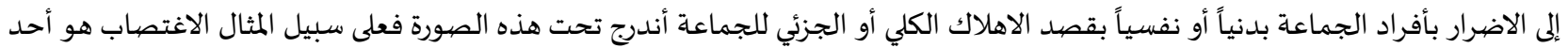

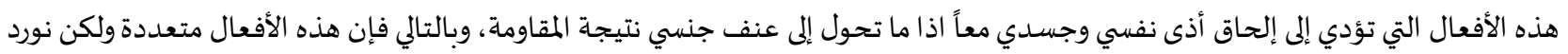

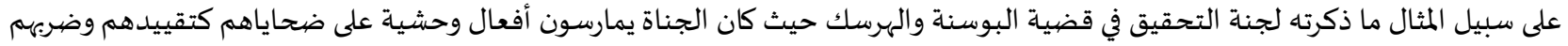

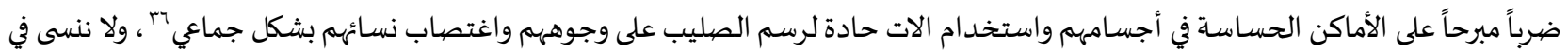

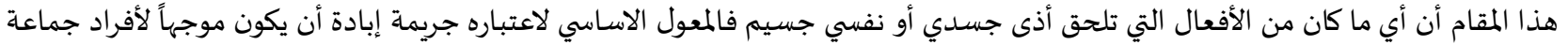

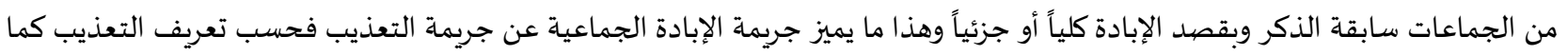

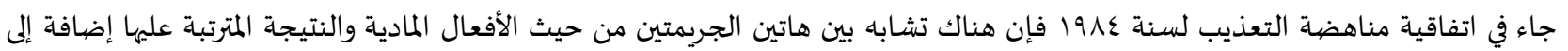

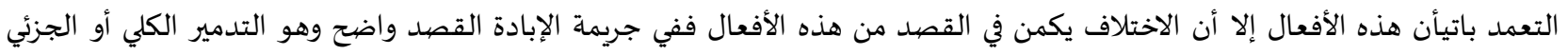

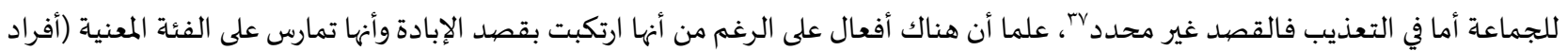

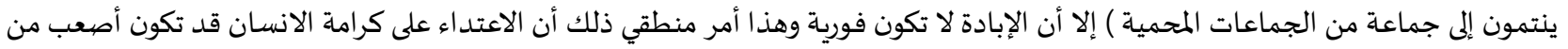
القتل الذي ينهي حياته فوراً.

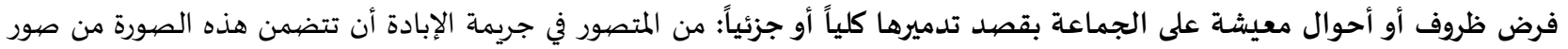

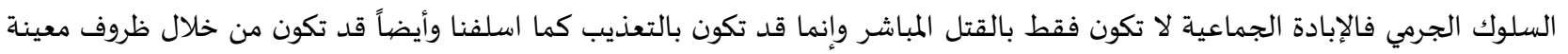

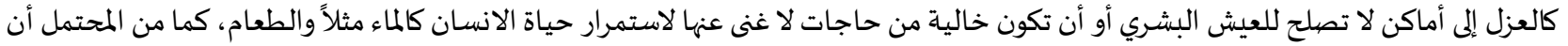

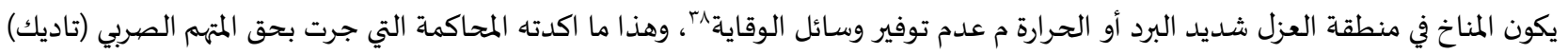

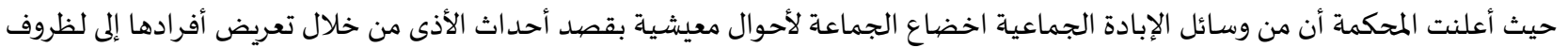

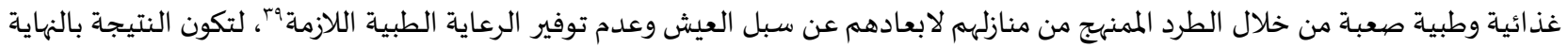

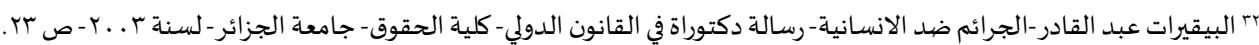

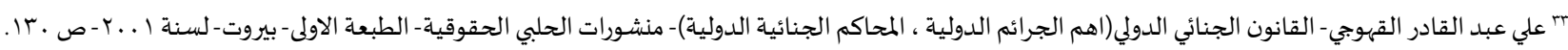

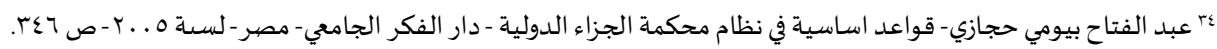

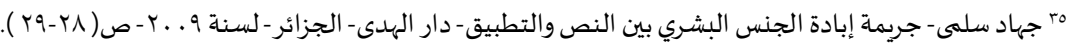

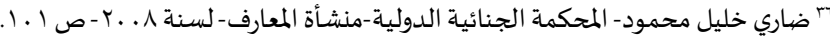

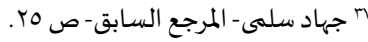

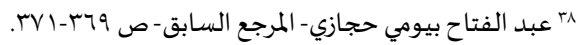

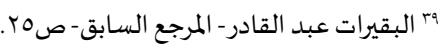


القضاء على الجماعة ولو بالمال. وكما هو مشار في المادة السادسة من اتفاقية منع جريمة الإبادة لسنة هع 19 فإن المسؤولية الجزائية تنهض بمجرد

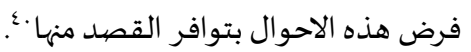

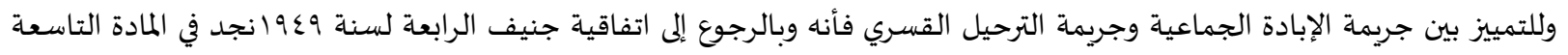

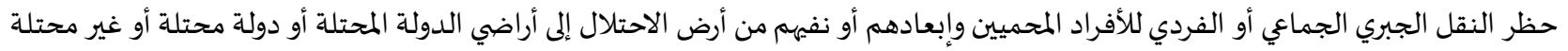

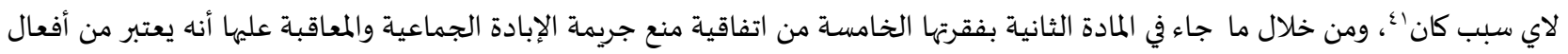

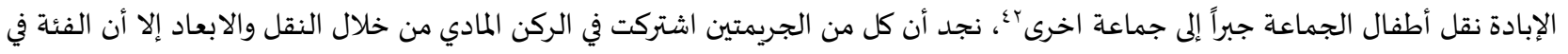

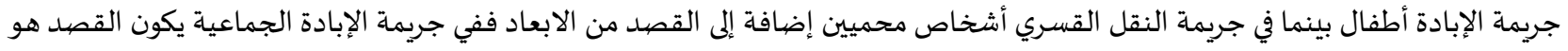

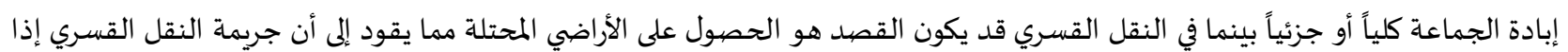

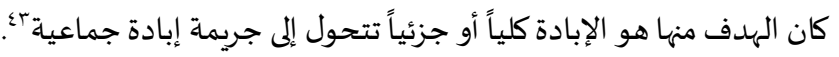

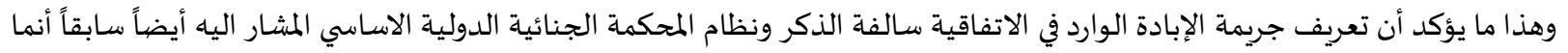

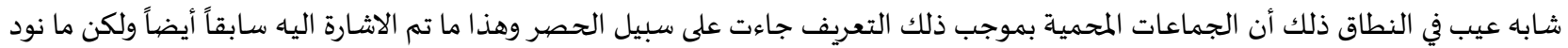

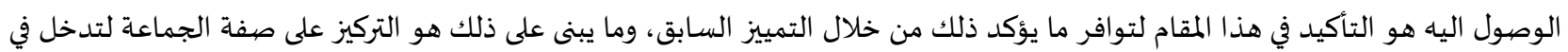

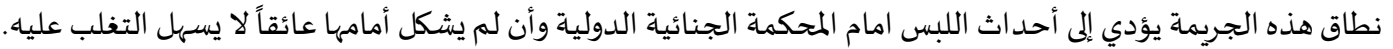

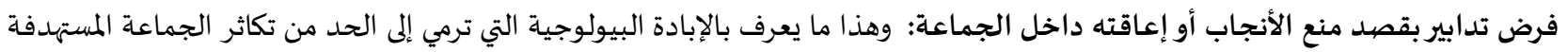

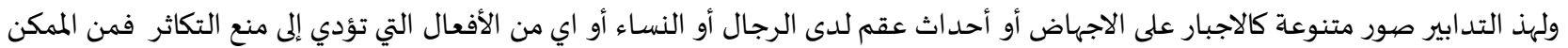

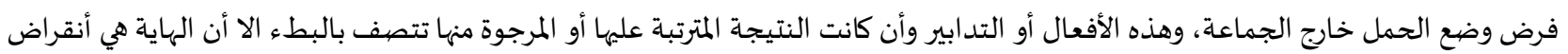

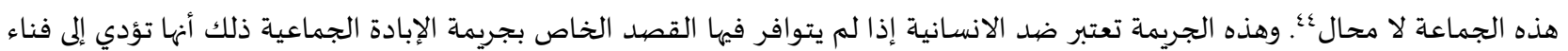

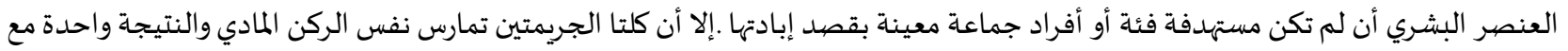
اختلاف الغرض وهذا يبقى المميز الأول والاخير لجريمة الإبادة الجماعية.

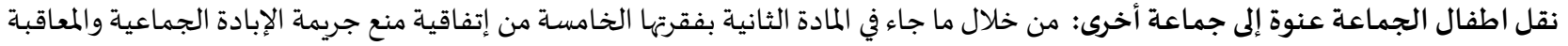

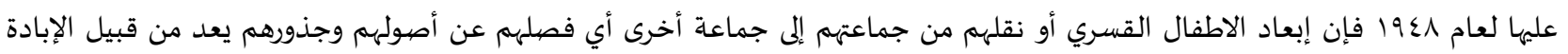

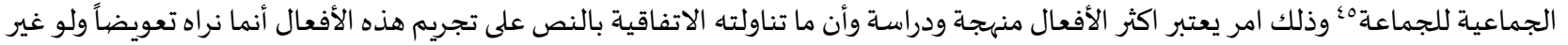

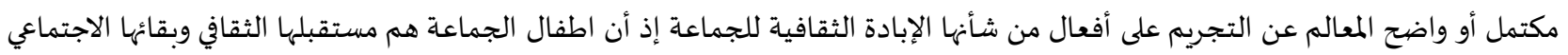

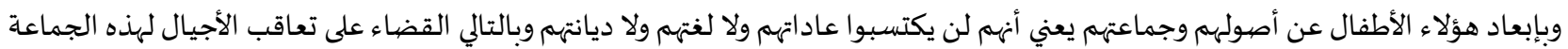

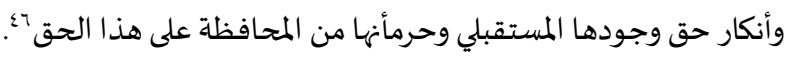

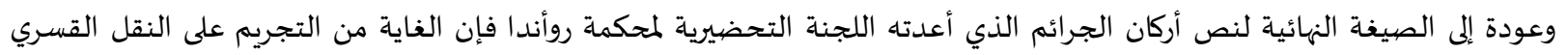

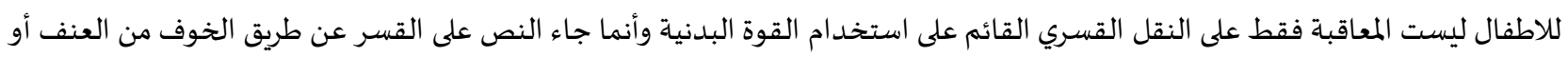

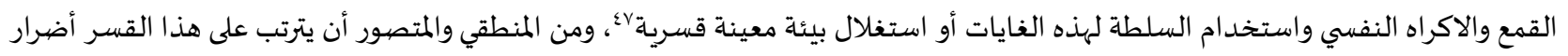

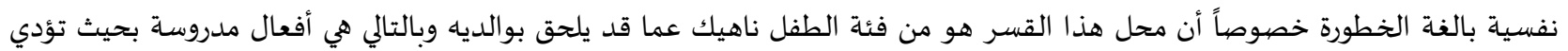

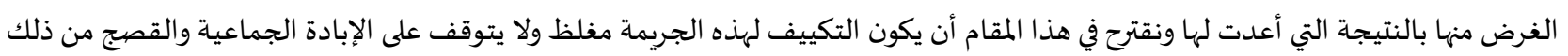

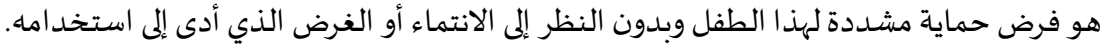

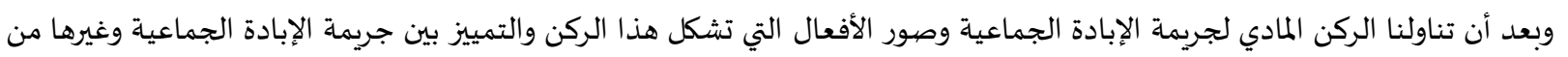

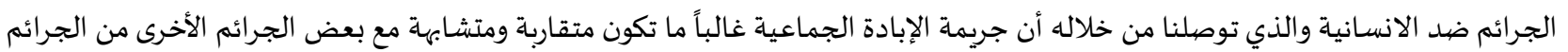

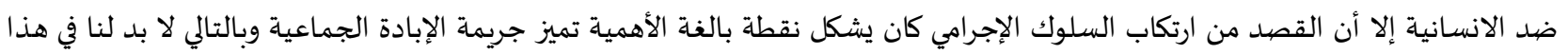

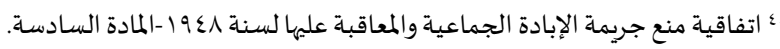

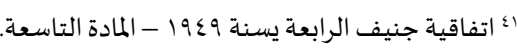

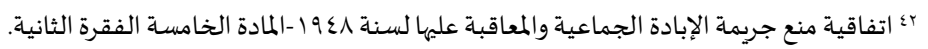

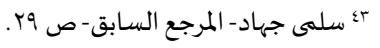

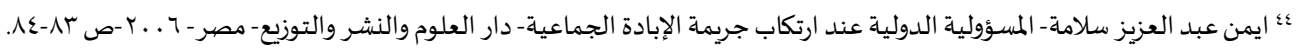

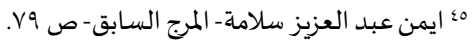

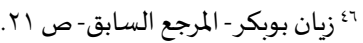

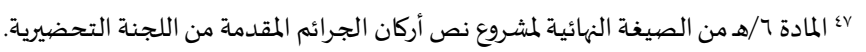




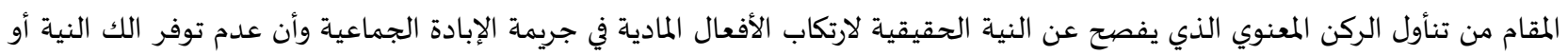
القصد قد يجعل من هذه الفعال جريمة اخرى من الجرائم ضد الإنساندية المعانية.

المطلب الثاني: الركن المعنوي لجريمة الإبادة الجماعية

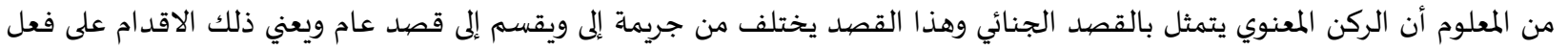

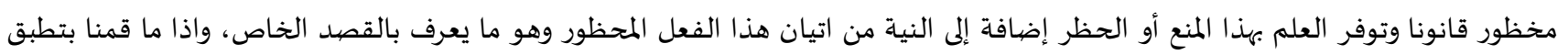

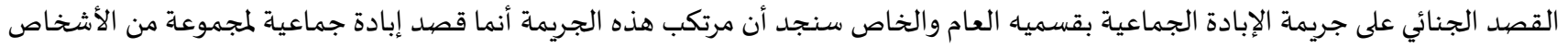

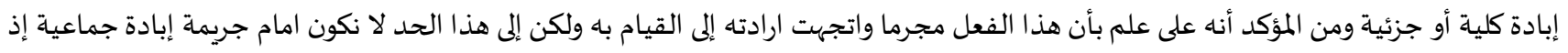

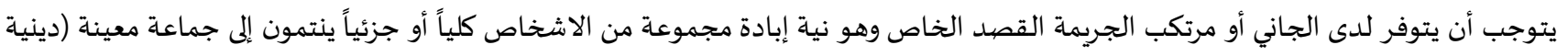

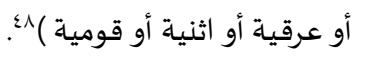

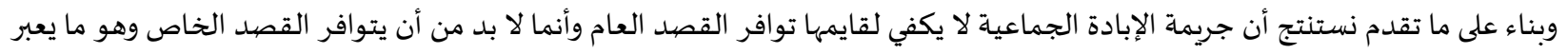

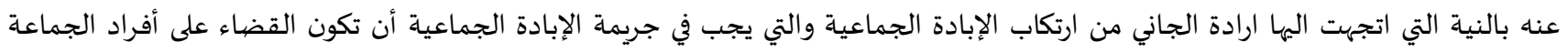

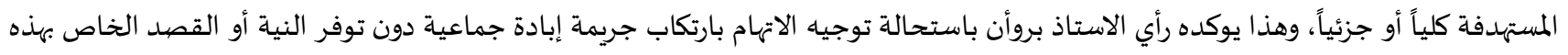

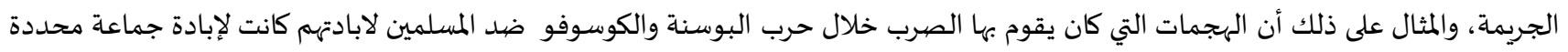

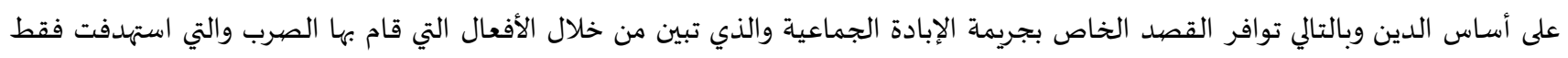
المسلمين

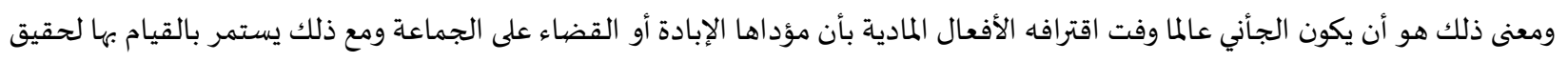

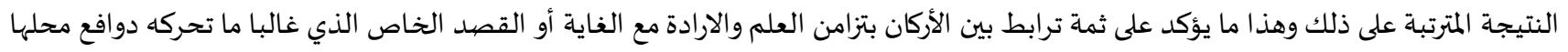

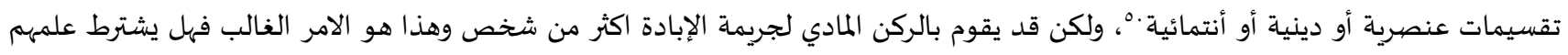

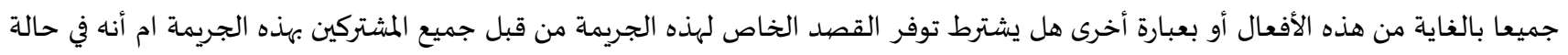

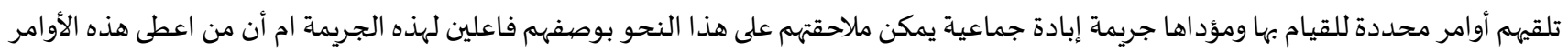

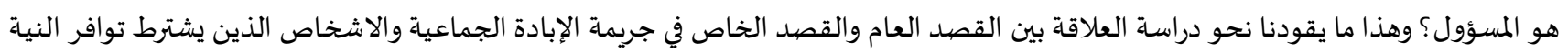
أو القصبد الخاص بجريمة الإبادة الجماعية لديهم.

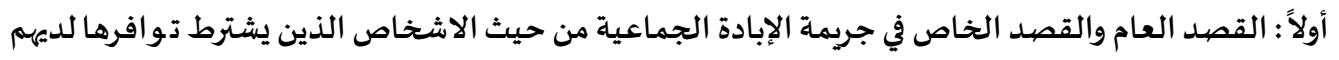

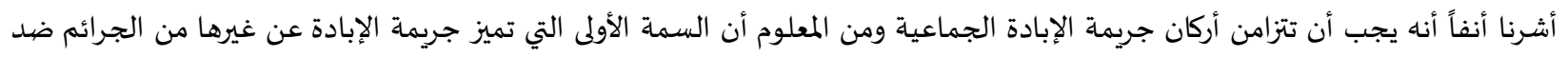

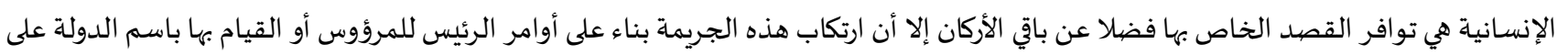

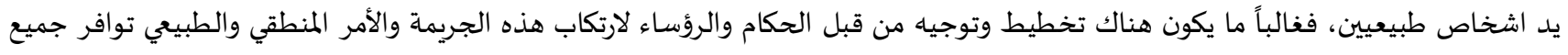

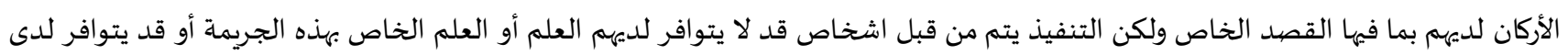

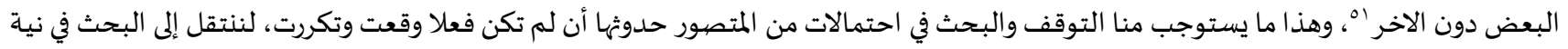

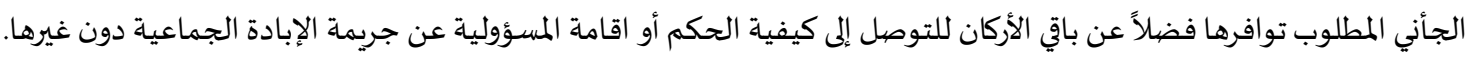

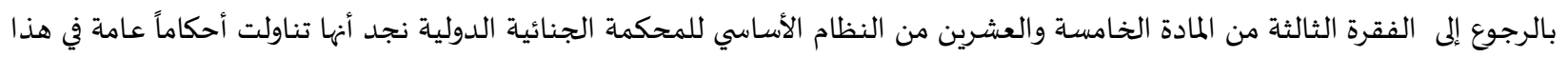

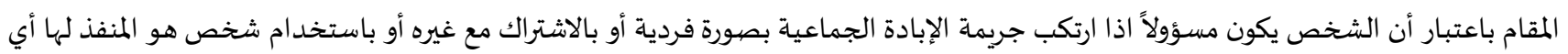

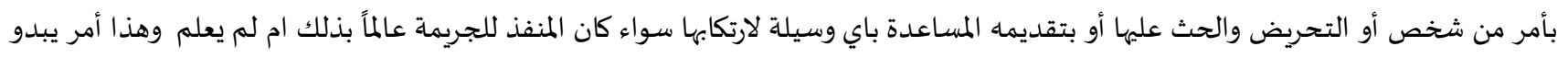

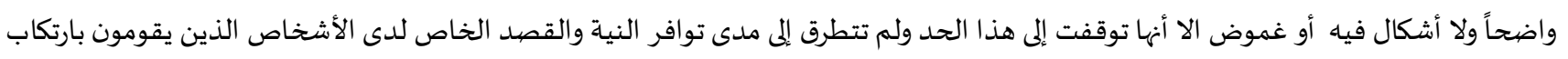

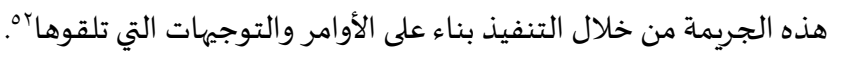

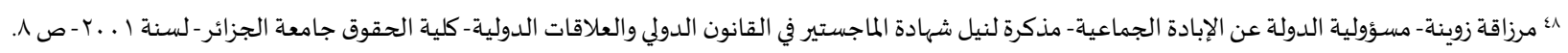

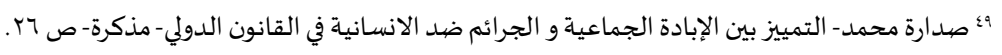

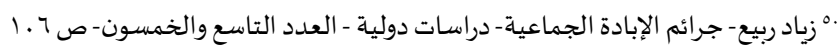

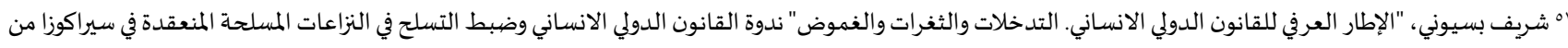
إن ror 
اثبات النية الخاصة بجريمة الإبادة الجماعية

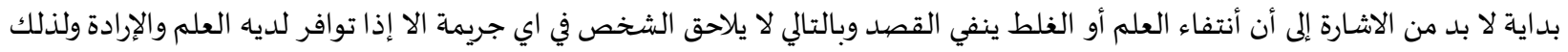

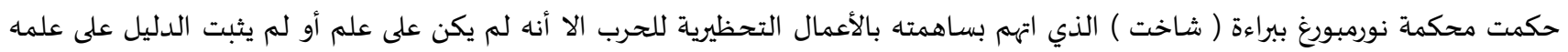

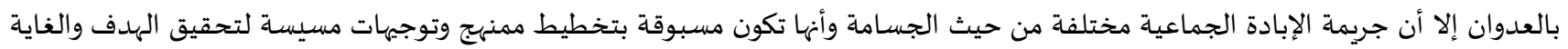

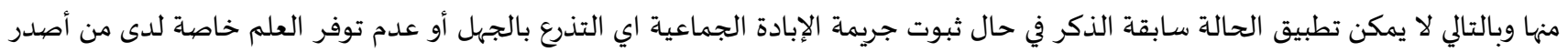

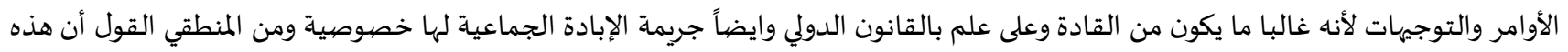

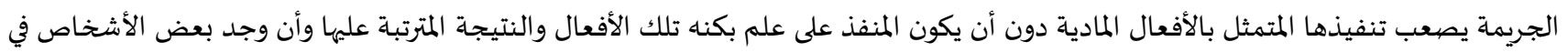

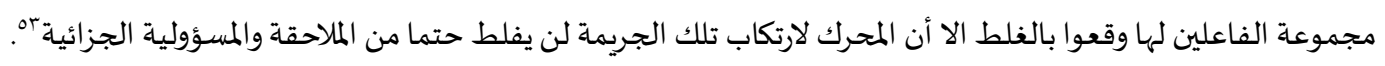

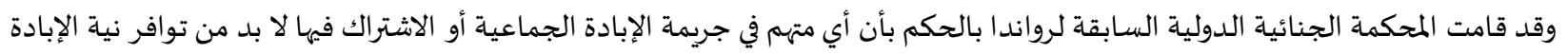

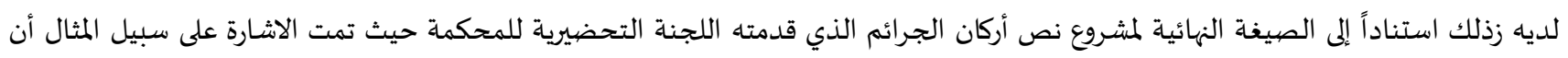

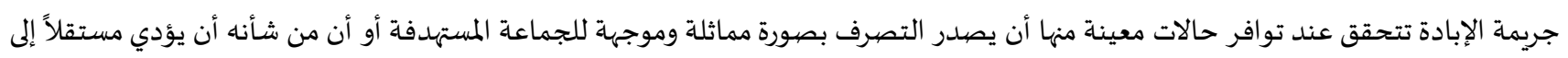
الإبادة الجماعية؛؛.

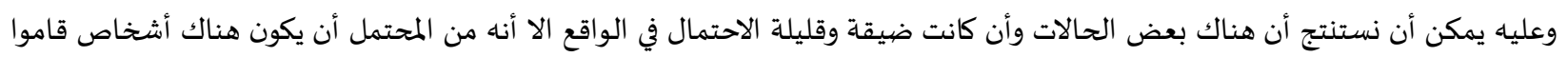

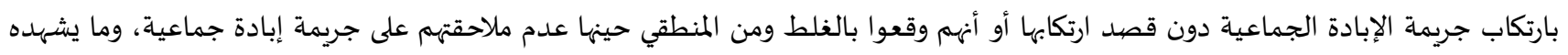

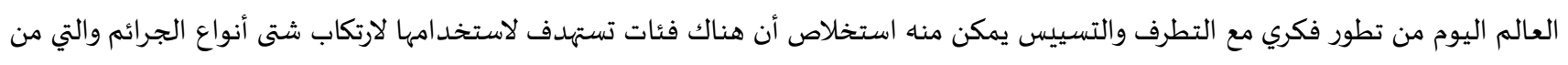

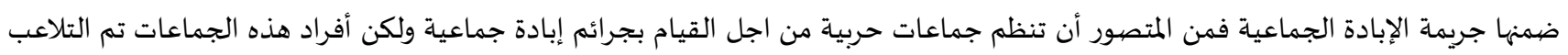

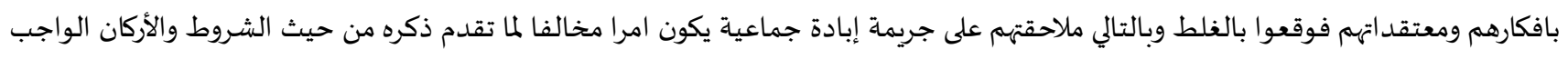
توافرها خصوصا نية الإبادة. ولكن ما هو الحكم في حالة توفر النية وعدم تحقق النتيجة اي في حالة كان المقدم على ارتكاب الأفعال المادية قاصداً ارتكاب جريمة إبادة جماعية ولكن لم تتحقق النتيجة ؟

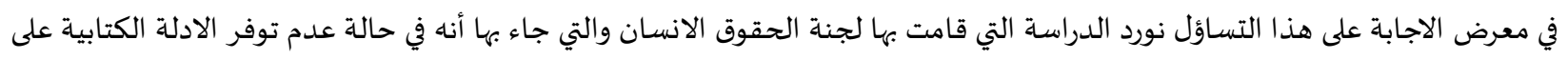

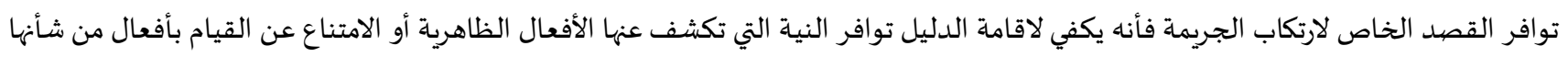

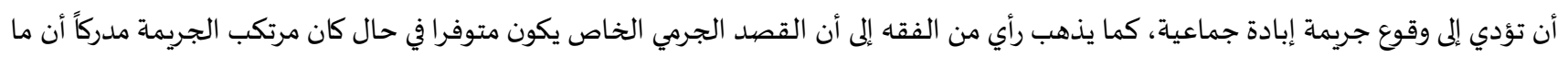

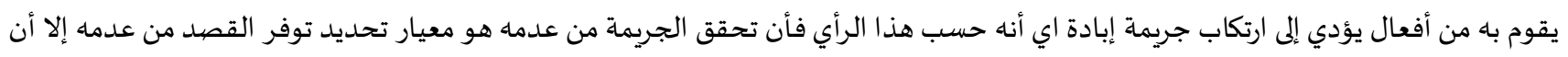

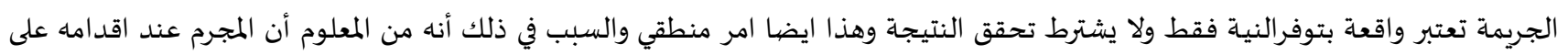

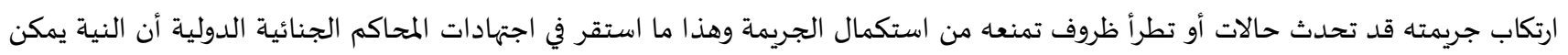

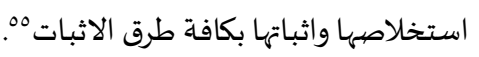

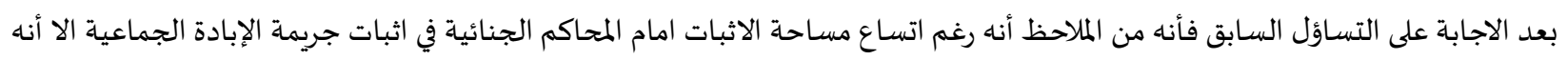

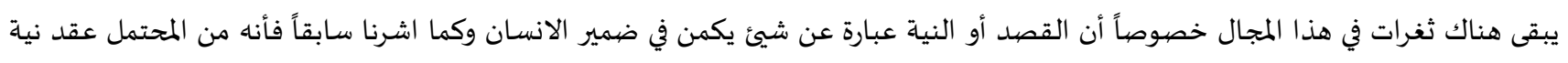

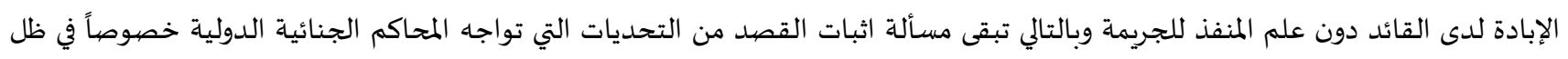

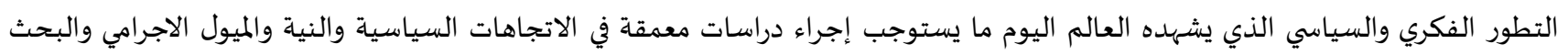

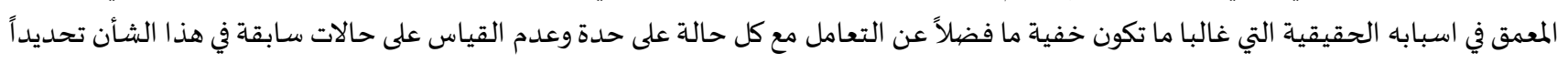

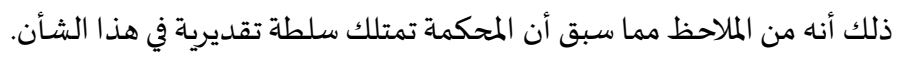

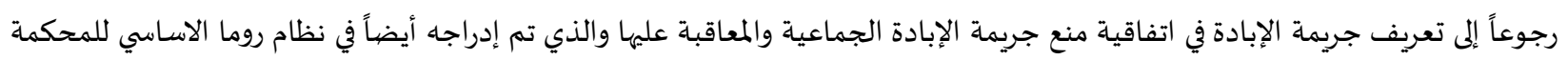

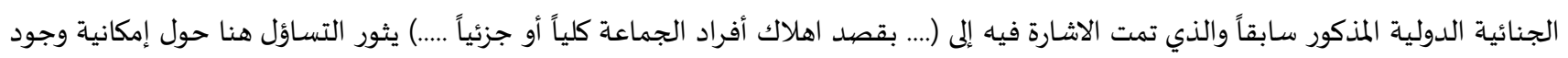

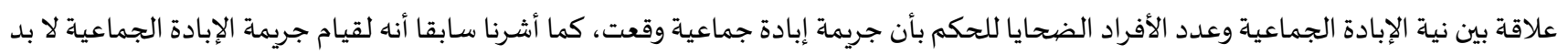

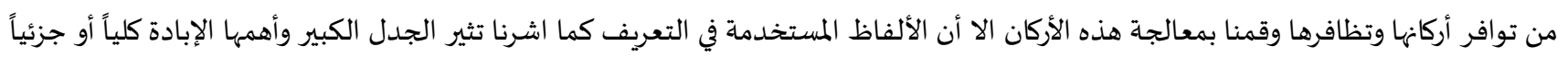

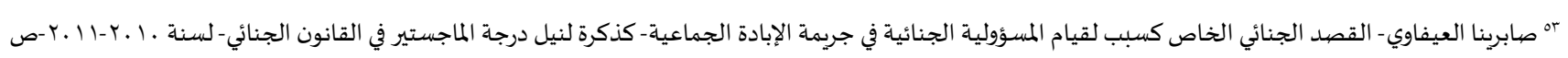

.VE-Vr

عه الصيعة النهائية لمشروع نص اركان الجرائم المقدم من اللجنة التحضيرية للمحكمة الجنائية الدولية الخاصة لرواندا - المادة السادسة الفقرة ( أ).

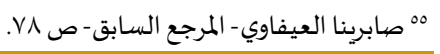


والذي يحمل على الفهم بأن جريمة الإبادة الجماعية قد تتوفر أركانها المتمثلة بالعلم والارادة والقصد الخاص الذادي الذي يرمي إلى إبادة الجماعة ولكن في حال

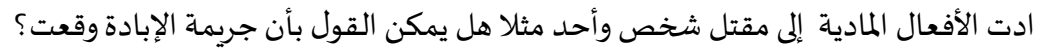

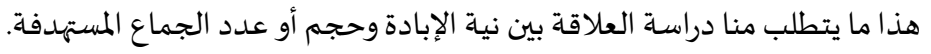

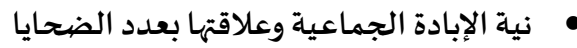

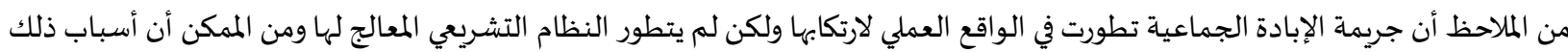

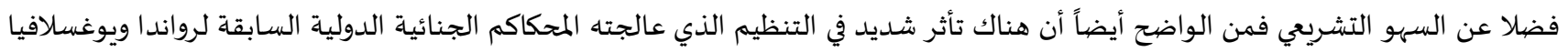

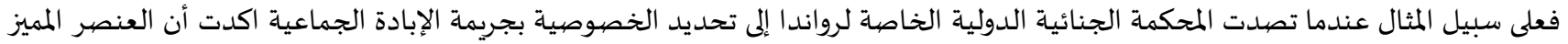

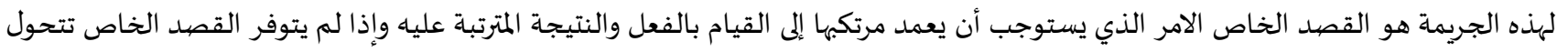

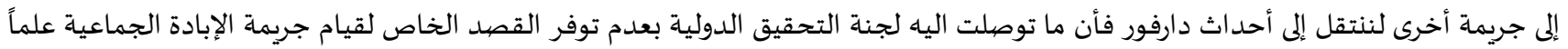

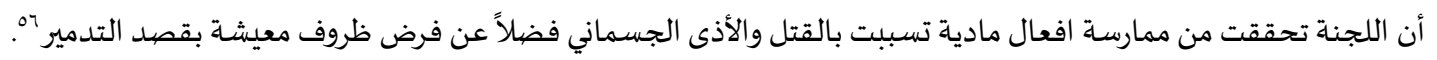

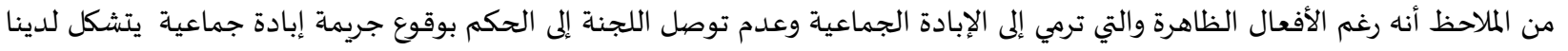

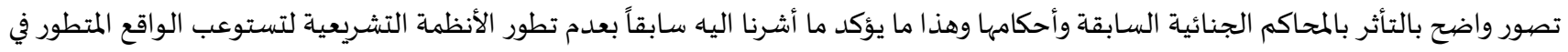

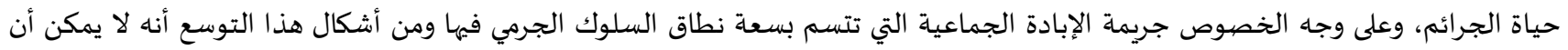

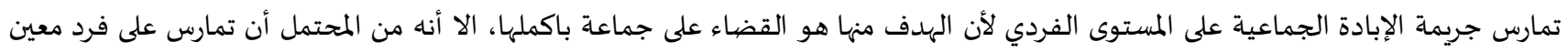

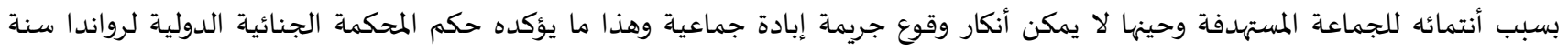

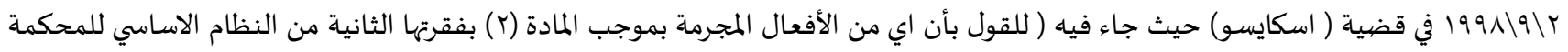

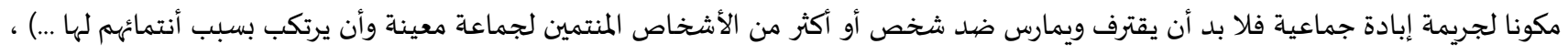

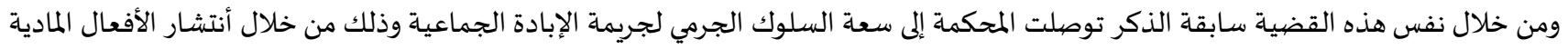

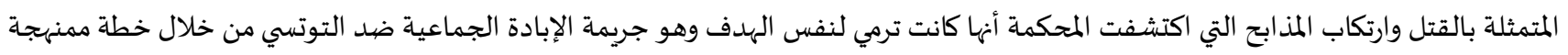

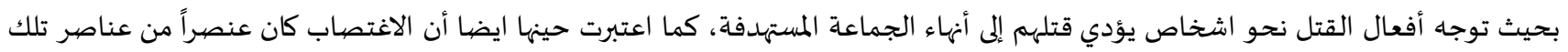

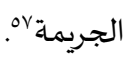

يتضيح لنا مما سبق مدى اتساع نطاق السلوك الجرمي في جريمة الإبادة الجماعية وهذا ما يقودنا للقول بأن هذه الجريمة ذات الخصهوصية

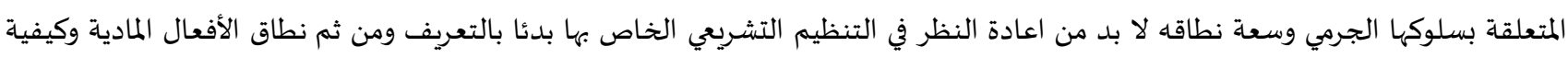

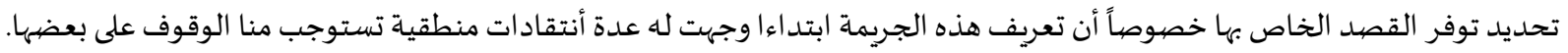

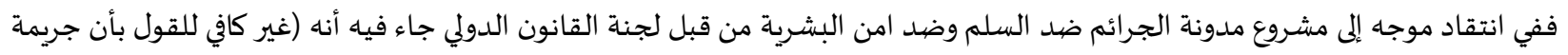

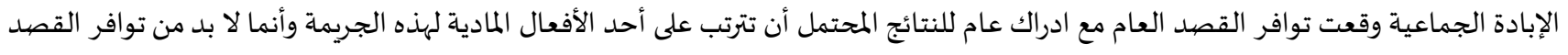

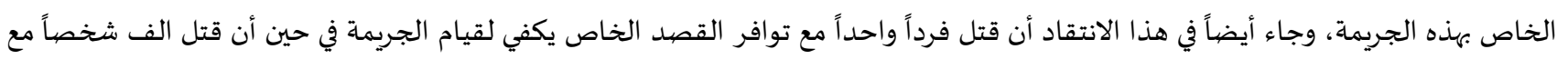

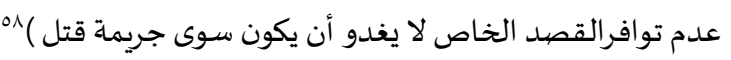

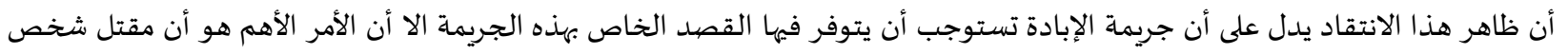

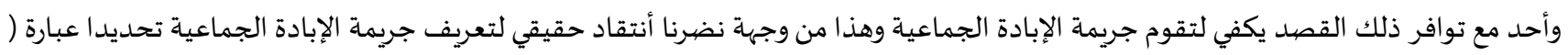

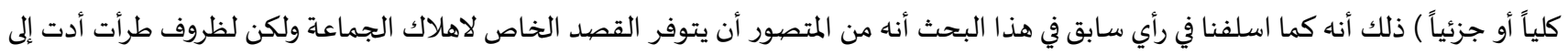

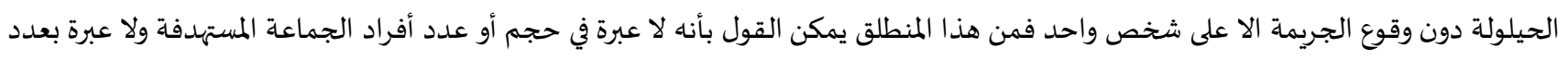

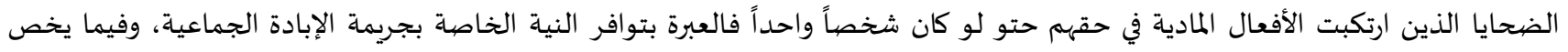

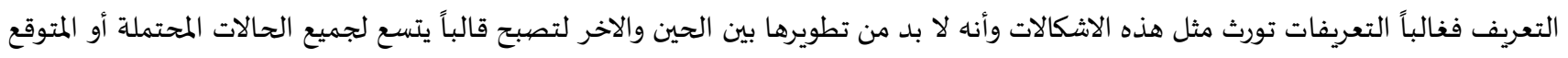
حدوثها في الواقع العملي الواسع للسلوك الاجرامي لجريمة الإبادة الجماعية.

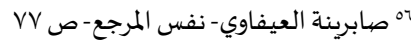

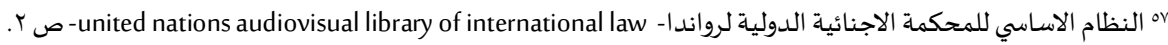

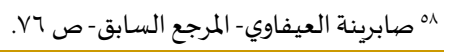


الخحاتمـة:

تناولنا في هذا البحث جريمة الإبادة الجماعية والتي تعد أخطر الجرائم ضد الإنسانية التي عرفتها الانسانية منذ عصور قديمة ولكن تطور العصر وموجوداته لم يؤثر على وصف هذه الجريمة فما زالت من ابشع وأكبر الجرائم جسامة لما تحمله في طياتها من أهداف خطيرة تتمثل في إبادة

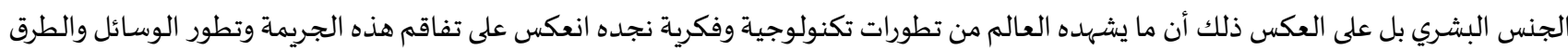

التي يمكن استخدامها لتنفيذها بصيورة يصعب الحكم معها على وقوع هذه الجريمة وقد توصلنا من خلال هذا البحث إلى النتائج والتوصيات التالية.

النتائج: أولاً: أن التعريف الذي تناولته اتفاقية منع جريمة الإبادة الجماعية والمعاقبة علهيا لسنة 19 19 أنما تعود حقيقة صياغتـا إلى بعض الصور التي كانت

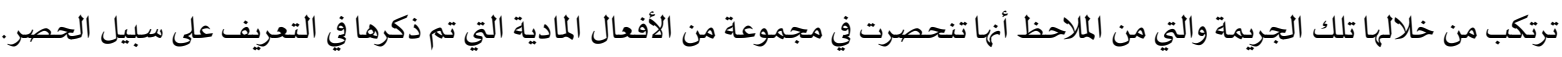

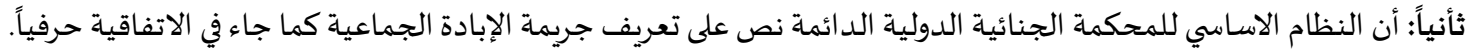

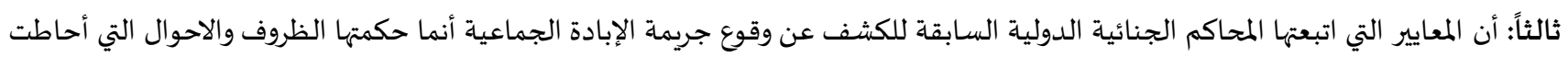
بتلك المحاكم أنذاك والتي تطلبت تلك المعاير التير المعائ.

التوصيات:

أولاً: نتمنى على المجتمع الدولي إعادة النظر في اتفاقية منع جريمة الإبادة الجماعية والمعاقبة عليها ونخص في ذلك النصيوص التي تناولت تعريف

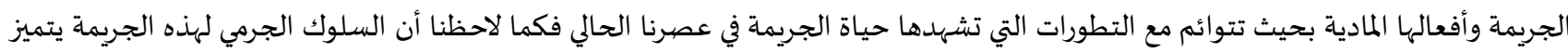

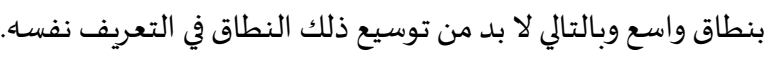

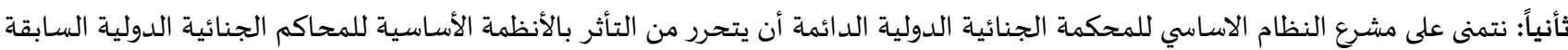

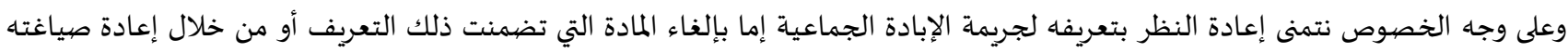

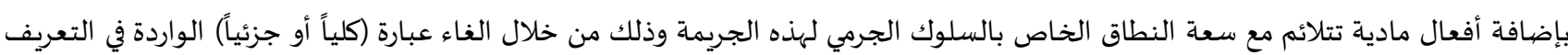

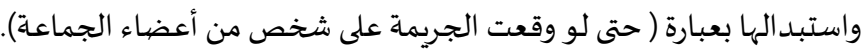

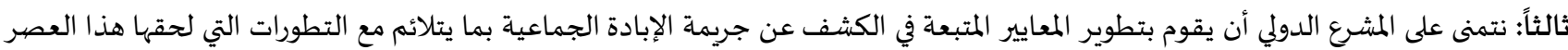

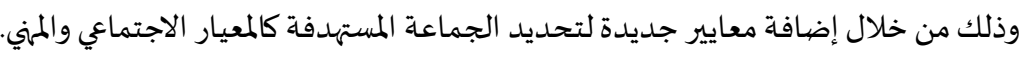

المراجع:

أولاً: المراجع العربية: الكتب

ا . بكة، سوسن تمرخان، الجرائم ضد الانسانية في ضوء أحكام النظام الاساسي للمحكمة الجنائية الدولية، الطبعة الأولى، بيروت، منشورات الحلبي الحقوقية، لسنة 7 . . أب.

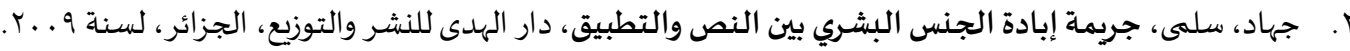

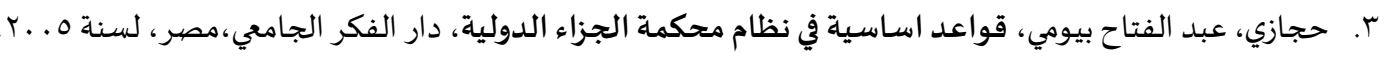

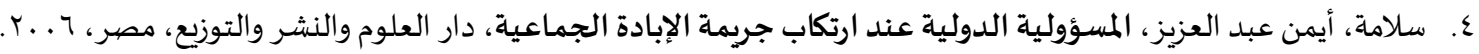

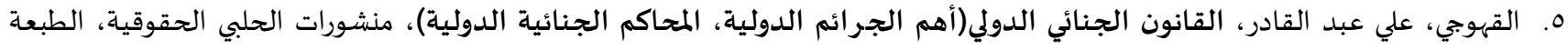

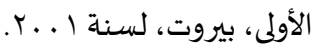

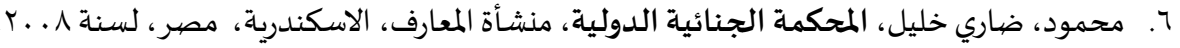

الاطروحات والرسـائل

ا . بسيوني شريف، (1991) الإطار العرفي للقانون الدولي الانساني. التدخلات والثفرات والغموض، ندوة القانون الدولي الانساني وضبط التسلح في النزاعات المسلحة المنعقدة في سيراكوزا.

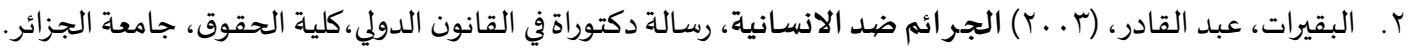

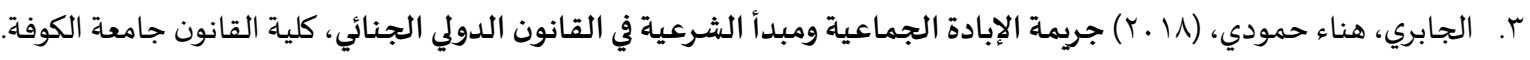




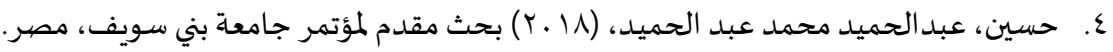

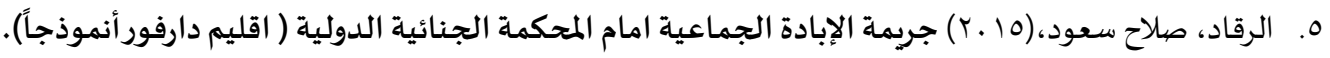

7.

الحادي والثلاثون.

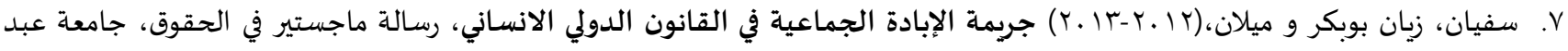
الرحمن ميرة ، بجاية.

1. السيد، خالد،جريمة الإبادة الجماعية، دكتوراة في القانون الجنائي-مركز الاعلام الامني.

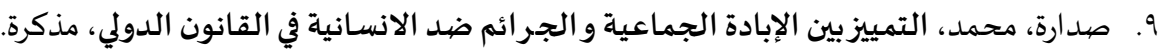

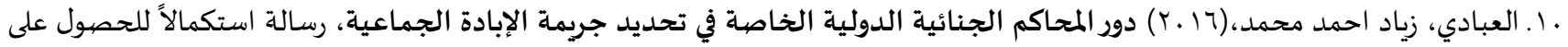

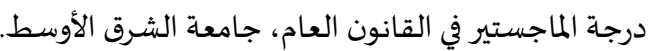

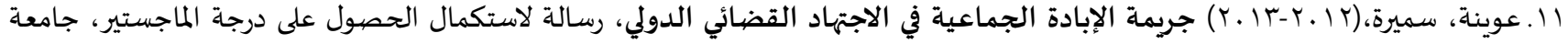

$$
\text { الحاج لخضر ، باتنة. }
$$

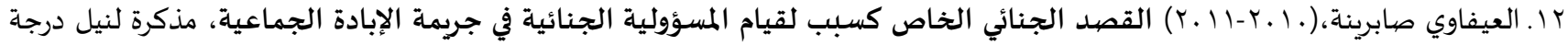

$$
\text { الماجستير في القانون الجنائي. }
$$

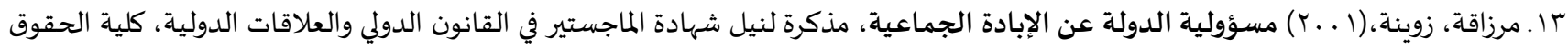
جامعة الجزائر.

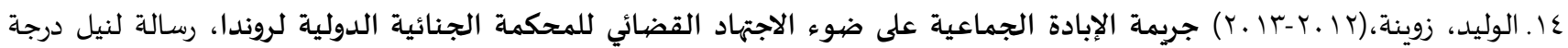

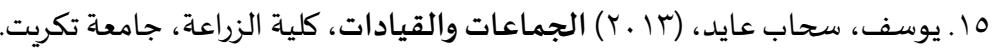

الدراسات والمقالات

ا . بيع، زياد، جرائم الإبادة الجماعية، دراسات دولية، العدد التاسع والخمسون.

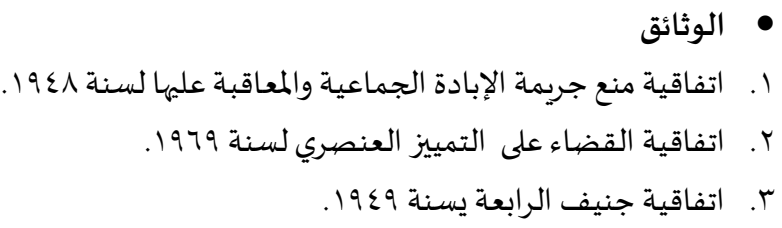

ع. الصيعة النهائية لمشروع نص أركان الجرائم المقدم من اللجنة التحضيرية للمحكمة الجنائية الدولية الخاصة لرواندا النظام الأساسي للمحكمة

الجنائية الدولية ليوغوسلافيا.

0. النظام الأساسي لمحكمة الجنائية الدولية لرواندا.

7. أنظام روما الاساسي 1991.

ثانياً : المراجع الأجنبية

[1] Senat de belqiqe, op cit.

[2] The international criminal tribunal for the former Yugoslavia-case no. ti,95,10, pt-1998. 
المجلة الدولية للدراسات القانونية والفقهية المقارنة

International Journal of Legal and Comparative Jurisprudence Studies (LCJS)

www.refaad.com

Journal Homepage: https://www.refaad.com/views/LCJS/Home.aspx

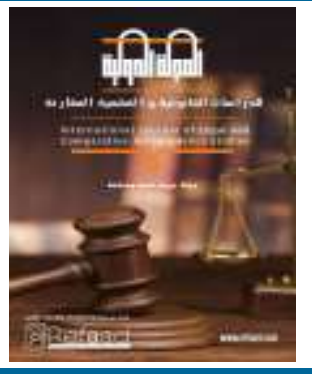

\title{
Identify the Crime of Genocide Under the Previous Criminal Courts that Extent of the Impact the Permanent at International Criminal Court
}

\author{
Omar Mohammad Musa Ismail \\ Assistant Professor, Department of Law, Shaqra University, KSA \\ omar.mi@su.edu.sa
}

Received Date : $1 / 3 / 2020$

Accepted Date : 25/3/2020

DOI : https://doi.org/DOI:10.31559/LCJS2020.1.1.1

\begin{abstract}
The subject of this research focuses on the crime of genocide in terms of the appearance of this crime and the definitions covered by international agreements such as the Convention on the Prevention and Punishment of the Crime of Genocide. The material and moral in terms of privacy that characterizes criminal behavior for them, which means specific and carefully defined groups and it was necessary to know the features that characterize this behavior from touching on the criteria by which the individuals or persons targeted are identified with these The crime and those who form their own federation called the group, and this research dealt with some glimpses that emerged through the analysis and depth in what is the crime of genocide in terms of the development of its tools and how to implement it, which shows results that can be used by the permanent International Criminal Court and the international legislator.
\end{abstract}

Keywords: Genocide; human rights; Criminal courts; International agreements; crime; Law

\section{References:}

[1] Al'bady. Zyad Ahmd Mhmd, Dwr Almhakm Aljna'yh Aldwlyh Alkhash Fy Thdyd Jrymt Alebadh Aljma'yh, Rsalt Astkmalaan Llhswl 'la Drjt Almajstyr Fy Alqanwn Al'am, Jam't Alshrq Alawst, (2016)

[2] 'wynh. Smyrh, Jrymt Alebadh Aljma'yh Fy Alajthad Alqda'y Aldwly, Rsalt Lastkmal Alhswl 'la Drjt Almajstyr, Jam't Alhaj Lkhdr, Batnh, (2012-2013)

[3] Al'yfawy Sabrynh, Alqsd Aljna'y Alkhas Ksbb Lqyam Alms'wlyh Aljna'yh Fy Jrymt Alebadh Aljma'yh, Mdkrh Lnyl Drjt Almajstyr Fy Alqanwn Aljna'y, (2010-2011)

[4] Bkh. Swsn Tmrkhan, Aljra'm Dd Alansanyh Fy Dw' Ahkam Alnzam Alasasy Llmhkmh Aljna'yh Aldwlyh, Altb'h Alawla, Byrwt, Mnshwrat Alhlby Alhqwqyh, Lsnh 2006.

[5] Albqyrat. 'bd Alqadr, Aljra'm Dd Alansanyh, Rsalh Dktwrah Fy Alqanwn Aldwly, Klyt Alhqwq, Jam't Aljza'er, (2003)

[6] Bsywny Shryf, Aletar Al'rfy Llqanwn Aldwly Alansany. Altdkhlat Walthghrat Walghmwd, Ndwt Alqanwn Aldwly Alansany Wdbt Altslh Fy Alnza'at Almslhh Almn'qdh Fy Syrakwza, (1998)

[7] Hjazy. 'bd Alftah Bywmy, Qwa'd Asasyh Fy Nzam Mhkmh Aljza' Aldwlyh, Dar Alfkr Aljam'y, Msr, Lsnh 2005.

[8] Hsyn. 'bdalhmyd Mhmd 'bd Alhmyd, Bhth Mqdm Lm'tmr Jam't Bny Swyf, Msr, (2018)

[9] Aljabry. Hna' Hmwdy, Jrymt Alebadh Aljma'yh Wmbda Alshr'yh Fy Alqanwn Aldwly Aljna'y, Klyt Alqanwn Jam't Alkwfh, (2018)

[10] Jhad. Slma, Jrymh Ebadt Aljns Albshry Byn Alns Walttbyq, Dar Alhda Llnshr Waltwzy', Aljza'r, Lsnh 2009.

[11] Mhmwd. Dary Khlyl, Almhkmh Aljna'yh Aldwlyh, Mnshat Alm'arf, Alaskndryh, Msr, Lsnh 2008. 
[12] Mrzaqh. Zwynh, Ms'wlyt Aldwlh 'n Alebadh Aljma'yh, Mdkrh Lnyl Shhadt Almajstyr Fy Alqanwn Aldwly Wal'laqat Aldwlyh, Klyt Alhqwq Jam't Aljza'er, (2001)

[13] Alqhwjy. 'ly 'bd Alqadr, Alqanwn Aljna'y Aldwly (Ahm Aljra'm Aldwlyh, Almhakm Aljna'yh Aldwlyh), Mnshwrat Alhlby Alhqwqyh, Altb'h Alawla, Byrwt, Lsnh 2001.

[14] Alrqad. Slah S'wd, Jrymt Alebadh Aljma'yh Amam Almhkmh Aljna'yh Aldwlyh (Aqlym Darfwr Anmwdjaan), (2015)

[15] Sdarh. Mhmd, Altmyyz Byn Alebadh Aljma'yh W Aljra'm Dd Alansanyh Fy Alqanwn Aldwly, Mdkrh.

[16] Sfyan. Zyan Bwbkr \& Mylan. Jrymt Alebadh Aljma'yh Fy Alqanwn Aldwly Alansany, Rsalt Majstyr Fy Alhqwq, Jam't 'bd Alrhmn Myrh, Bjayh, (2012-2013)

[17] Slamh. Aymn 'bd Al'zyz, Alms'wlyh Aldwlyh 'nd Artkab Jrymt Alebadh Aljma'yh, Dar Al'lwm Walnshr Waltwzy', Msr, 2006.

[18] Alsyd. Khald, Jrymt Alebadh Aljma'yh, Dktwrah Fy Alqanwn Aljna'y-Mrkz Ala'lam Alamny.

[19] Alwlyd. Zwynh, Jrymt Alebadh Aljma'yh 'la Dw' Alajthad Alqda'y Llmhkmh Aljna'yh Aldwlyh Lrwnda, Rsalt Lnyl Drjt Almajstyr, (2012-2013)

[20] Ywsf. Shab 'ayd, Aljma'at Walqyadat, Klyt Alzra'h, Jam't Tkryt, (2013)

[21] Zwyr. Antzar Rshyd, M'aljt Jrymt Alebadh Aljma'yh Al'almyh (Al'raq Anmwdj), Klyt Alhndsh, Jam't Wast, Mjlt Klyt Altrbyh Al'dd Alhady Walthlathwn, (2018) 